HID 40 (2013)

\title{
NOTARIOS CATALANES EN ROMA: LOS NOTARIOS MATRICULADOS EN EL ARCHIVO DE LA CURIA (1508-1671)*
}

\author{
CATALAN NOTARIES IN ROME: THE NOTARIES REGISTERED IN THE \\ CURIA'S ARCHIVE (1500-1671)
}

\author{
Daniel Piñol Alabart \\ Universidad de Barcelona \\ danielpinol@ub.edu
}

RESUMEN: Este artículo estudia la presencia en Roma de un colectivo de notarios catalanes durante los siglos XVI y XVII. Se trata de los notarios matriculados en el colegio de escritores del Archivo de la Curia, una institución que tenía la función de crear notarios. Todo notario extranjero que llegaba a Roma tenía que matricularse en este colegio. En los libros de matrícula se insertan diversos datos de cada uno de los notarios, además del signum. Se plantea también la hipótesis de que estos notarios trabajen en Roma ejerciendo el oficio notarial. Por ello se analiza la actividad de algunos de estos notarios en la ciudad de Roma a través de la documentación notarial conservada actualmente en los archivos romanos.

PALABRAS ClAVE: notariado catalán, siglos XVI-XVII, Roma, curia pontificia, actividad notarial.

ABSTRACT : This article studies the presence in Rome of a group of Catalan notaries in the sixteenth and seventeenth centuries. They are the notaries registered in the Archive's Curia of writers College, an institution to creating notaries. All foreign notary who came to Rome had to register in this College. In the enrollment's books they are data from the notaries, and his signum. It also raises the hypothesis that these notaries work in Rome exerting the notarial function. For this reason is analyzed the activity of some of these notaries in the city of Rome through the notarial documents today conserved in the Roman archives

KEYwORDS: catalan notariat, 16th-17th century, Rome, Pontificia curia, notarial activity.

* Este artículo es resultado de la investigación llevada a cabo con el proyecto 2007 BE-100245, de la Generalitat de Catalunya. También se ha beneficiado del proyecto PGIR-08/09 de la Universitat de Barcelona. 


\section{INTRODUCCIÓN ${ }^{1}$}

Nadie duda del papel que juega la Ciudad Eterna a lo largo del tiempo en múltiples aspectos. Tampoco es necesario resaltar la importancia de las aportaciones a la Historia que se hacen desde Roma en el ámbito de la política, del derecho, de la cultura..., y también de la religión y la Iglesia. Pero además de estos aspectos debemos señalar también que Roma es un punto de encuentro, capital de la Cristiandad y, a partir de la época moderna, del catolicismo. Este factor hace que gentes de toda procedencia y condición vayan hasta la ciudad movidos por diferentes motivos: peregrinación, política, economía, trabajo... La población romana en la época moderna está formada por habitantes autóctonos pero también por numerosos grupos extranjeros. Según un censo realizado el 1527, en vísperas del Sacco, los cabezas de familia españoles son 210 de un total de 9.328, englobando bajo esta denominación a todos los procedentes de los reinos hispánicos. En realidad solamente aparece un cabeza de familia censado bajo el apelativo de catalano, lo cual nos lleva a afirmar que el concepto spagnolo tenía un sentido muy amplio ${ }^{2}$. Así pues entre los grupos foráneos que habitan en Roma a principios del siglo XVI destacan los procedentes de los reinos hispánicos. Llegaron a la capital con los Borja $^{3}$; algunos más notables formarían parte de la corte pontificia ${ }^{4}$ y todos configuran la facción extranjera dominante a lo largo de los siglos XVI y XVII, según palabras de Thomas J. Dandelet ${ }^{5}$. Aunque ya se tienen noticias de la existencia de un hospital perteneciente a la Corona de Aragón, a finales del siglo XIV ${ }^{6}$, no es hasta un siglo después en que lo hispánico se hace más presente en Roma: “(...) San Pietro in Montorio es el resultado del mecenatismo de los Reyes Católicos y Santa María de Montserrat se benefició del apoyo económico tanto de la Corona como de la rica comunidad de mercaderes y hombres de negocios catalanes residentes en la ciudad..."7. Estos hombres de negocios catalanes, y también una

1. Abreviaturas utilizadas: Archivio Segreto Vaticano (ASV). Archivio Segreto Vaticano/ Sacra Congregatione Concilii, Relationes Diocesium (ASV, SCC, Rel. Dioc.). Archivio Storico Capitolino di Roma/ Archivio Urbano (ASC, AU). Archivio di Stato di Roma / Collegio dei Notai Capitolini (ASS, CNC). Archivo Histórico Archidiocesano de Tarragona (AHAT). Archivo Histórico de Tarragona (AHT).

2. E. LEE. (ed.) 'Descriptio Urbis'. The Roman Census of 1527, Roma: Ed. Bulzoni, 1985, pp. 310-312.

3. J. DELUMEAU. Rome au XVIe siècle, París: Hachette, 1975, pp. 50-51.

4. J. RIUS SERRA. "Catalanes y aragoneses en la Corte de Calixto III", Analecta Sacra Tarraconensia, III(1927), pp. 120-330.

5. Th.J. DANDELET. La Roma española (1500-1700), Barcelona: Ed. Crítica, 2002, pp. 24; 139.

6. J. VIEILLARD. "Notes sur l'hospice Saint-Nicolas des Catalans à Rome au Moyen Age", en Mélanges d'Archéologie et d'Historie, 50(1933), pp. 183-193. J. FERNÁNDEZ ALONSO. "Las iglesias nacionales de España en Roma. Sus orígenes", Anthologica Annua 4(1956), pp. 9-122; ID., "E1 hospital de San Nicolás de los Catalanes en Roma. Nuevos documentos de Nicolás Conill”, Anthologica Anпиа 30-31 (1983-1984), pp. 363-377; J. VINCKE. "Inicios del hospital Cathalanorum et Aragonensium en Roma”, Hispania Sacra 11(1958), pp.139-156. D. CARRIÓ-INVERNIZZI. "Los catalanes en Roma y la Iglesia de Santa María de Montserrat (1640-1670)", Pedralbes 28(2008) pp. 571-584.

7. M. VAQUERO PIÑEIRO. La renta y las casas. El patrimonio inmobiliario de Santiago de los españoles de Roma entre los siglos XV y XVII, Roma: L’Erma di Bretschneider, 1999, p. 19. 
nutrida representación de artesanos junto a algunos eclesiásticos, están ligados a la iglesia nacional de la Corona de Aragón, Santa María de Montserrat; por el contrario, la iglesia nacional castellana es el núcleo que aglutina a los eclesiásticos castellanos de la Curia pontificia y de la Cámara Apostólica ${ }^{8}$.Los mercaderes catalanes tienen además otro punto de apoyo cuando se crea el consulado catalán en Roma, en el año 1484. Algunos catalanes vienen de Nápoles y, como no tienen un banco propio, se asientan cerca de florentinos y genoveses, en la zona de Campo de Fiori, cerca de la iglesia de Montserrat. También instalan casas y almacenes en la ribera del Tíber, en el Trastevere ${ }^{9}$. La presencia de estos mercaderes catalanes alcanza su máximo esplendor entre los años 1506 y 1518, según se comprueba en los registros de la Cofradía de la Virgen de Montserrat, en que el 44\% son catalanes, el 30\% valencianos, el $14 \%$ aragoneses, el 5\% mallorquines; el resto son de diversas procedencias. En la Cofradía un $42 \%$ de sus miembros eran clérigos, el $21 \%$ menestrales y pequeños comerciantes, el $16 \%$ mercaderes-banqueros, un $10 \%$ formado por notarios, auditores y funcionarios de Curia, y un $9 \%$ de servidores. La actividad de estos mercaderes entra en decadencia definitiva en la década de los 40 del siglo $\mathrm{XVI}^{10}$. Estas evidencias llevan a Benedetto Croce a afirmar lo siguiente:

(...)Cuanto de español había en Italia, particularmente en Nápoles y en Roma, se reavivó en los primeros años de aquel siglo y España parecía invadir Italia no sólo con sus armas, si no con todo su espiritu nacional, superando la tradición, las costumbres y hasta la misma cultura italiana ${ }^{11}$.

Desde el punto de vista político es necesario indicar las estrechas relaciones que se establecen entre Roma y la monarquía hispánica, que arrancan a mediados del siglo XV, y que perdurarán con fuerza hasta el advenimiento de Urbano VIII al solio pontificio, momento en que se iniciará la decadencia de estas relaciones y de la preponderancia hispana en la urbe ${ }^{12}$. Pero ya a finales del siglo XVI comienza a enrarecerse el ambiente contra los españoles, acusándoles junto los acaparadores, los aprovechados y la aristocracia, de las desgracias que hay en la ciudad ${ }^{13}$.

\footnotetext{
8. IDEM, p. 18.

9. Th.J. DANDELET. La Roma española ..., p. 45.

10. Sobre los mercaderes catalanes vid. M. VAQUERO PIÑEIRO. "La presencia de los españoles en la economía romana (1500-1527)", En la España medieval 16(1993), pp. 287-305. ID. "Mercaderes catalanes y valencianos en el consulado de Roma", Revista d'Història Medieval 9(1998),

11. B. CROCE. España en la vida del Renacimiento, Sevilla: Ed. Renacimiento, 2007, p. 161.

12. Th.J. DANDELET. La Roma española ..., pp. 231-246.

13. J. DELUMEAU. Rome..., pp. 148-149.
} pp. 155-169. 


\section{Los notarios catalanes del Archivo de la Curia}

De los colectivos que se insertan entre la población extranjera que vive en Roma nos fijamos ahora en un grupo concreto formado por notarios catalanes. Las razones que nos mueven a ello arrancan del interés por la historia del notariado catalán, por la praxis y el análisis de la actividad de los notarios en Catalunya. Este interés nos lleva ahora a Roma entre los años 1508 y 1671, siguiendo los pasos de estudios anteriores que abordan también esta cuestión. J. Lesellier estudió en 1933 los notarios franceses en Roma entre los años 1507-1625, notarios que pertenecían a la Curia Romana ${ }^{14}$. Por ello es muy interesante el trabajo ya que aporta datos sobre el funcionamiento del notariado en Roma en la época moderna. Es un trabajo fundamental para comprender el mundo complejo del notariado en la Roma moderna y para entender la presencia de notarios extranjeros en la ciudad. Pero sobre todo es importante porque explica el funcionamiento del colegio de los escritores del Archivo de la Curia, colegio estrechamente relacionado con los notarios objeto del presente artículo. Años más tarde M. Luisa San Martini realizó un completo estudio sobre este colegio, aportando nuevos datos sobre su organización y funcionamiento, así como el nombre de los notarios que lo configuraban ${ }^{15}$. Nuevamente debemos afirmar que estamos ante un trabajo fundamental para comprender el entramado del notariado romano moderno. Finalmente debemos citar la aportación de Pilar Pueyo sobre los notarios altoaragoneses en Roma y que sigue la tónica de los trabajos anteriores ${ }^{16}$. Estos trabajos, sobre todo el último, nos sugerían de forma clara realizar un trabajo similar, centrado esta vez en los notarios catalanes.

El objetivo de este artículo es aportar datos sobre la presencia de notarios catalanes en Roma en la época moderna. Para ello se ha consultado el fondo Santini, del Archivio Segreto Vaticano, tal como han hecho los citados trabajos. En este fondo se conserva parte de la documentación del colegio de los escritores del Archivo de la Curia. Este colegio, creado en 1507 por Julio II como un cuerpo de élite dentro de la Curia para el control de la documentación notarial, también tenía la potestad de nombrar notarios. Según la bula de creación, todo notario extranjero que quisiera ejercer su oficio en la ciudad debía matricularse en el colegio. Estas matrículas están insertadas en los libros conservados en este fondo archivístico y proporcionan datos de primer orden sobre los notarios matriculados. Los libros conservados son 8 y abarcan diversos períodos entre los siglos XVI y XVII, dejando algunas notables lagunas: n. 23 (1507-1519); n. 24(1539-1549); n. 25(15491561); n. 26(1577-1587); n. 27(1649-1660); n. 28(1661-1693); n. 29(1747-1809); n. 226( 1693-1746). Lesellier, no obstante, no tuvo en cuenta este último y explicó

14. J. LESELLIER "Notaries et archives de la Curie Romaine (1507-1625): les notaires français à Rome", Mélanges d'Archéologie et d'Histoire 50(1933), pp. 250-275.

15. M.L. SAN MARTINI BARROVECCHIO. "Il collegio degli scrittori dell'Archivio della Curia romana e il suo ufficio notarile (secoli XVI-XIX)", en Studi in onore di Leopoldo Sandri, Roma: Scuola speciale per archivisti e bibliotecari dell’Università di Roma, 1983, pp. 847-872.

16. P. PUEYO. "Notarios altoaragoneses en Roma (1507-1625)", en XIV Congresso di Storia della Corona d'Aragona, vol. IV, Sassari: Carlo Delfino Editore, 1990, p. 251-264. 
que se conservaban 7 y desaparecieron 6 . En este mismo fondo se conservan también otros documentos relacionados con el colegio. Así tenemos un formulario para el colegio (n. 228) y dos libros de actas de las reuniones de dicha institución (n. 30, años 1551-1566; n. 231, años 1605-1608).

Para suplir las lagunas que dejan los registros desparecidos se han consultado los libros de las Relationes ad limina correspondientes a esos siglos y en los que aparecen los nombres de los notarios que validaban las actas de dichas visitas. Algunos de los notarios que suscriben dicha documentación lo hacen completando la suscripción con la fórmula in archivio Romane curie descriptus. Estos notarios de las Relationes pertenecen a las diócesis de Barcelona ${ }^{17}$, Lleida ${ }^{18}$, Tarragona ${ }^{19} \mathrm{y}$ Tortosa $^{20}$, resultando un total de 9 notarios, algunos de los cuales se repiten en más de un documento.

De Barcelona firma el acta de la visita ad limina Jaume Morer, notario público por autoridad apostólica el día 27 de enero de 1635. De Lérida son los notarios Valeri Gallinat, Josep Jordà y Antoni del Puy. El primero valida dos actas, la primera el 22 de febrero de 1618 como notario público por autoridad apostólica, pero no consta que esté matriculado en el Colegio de Escritores del Archivo de la Curia. Sí que consta esta condición en el acta del 22 de julio de 1626. Este mismo notario firma un acta de la relatio de la diócesis de Tarragona del 25 de septiembre de 1635 y hace constar que es un presbítero de la diócesis de Lérida, notario público por autoridad apostólica y in Sacro Romano Archivio descriptus. El segundo notario ilerdense es Josep Jordà, notario público por autoridad apostólica y real y miembro del colegio de notarios públicos de Lleida (acta del 20 de mayo de 1692). El otro notario ilerdense firma el documento el 20 de enero de 1717. Se trata del doctor Antoni del Puy, habitante de Monzón y notario público por autoridad apostólica. Los datos cronológicos de este último fedatario nos sitúan fuera de los datos que encontramos en los libros de matrícula. En las relationes tarraconenses consta el notario Joan Pau Oller validando dos documentos. El primero lo hace el 11 de octubre de 1614, indicando que es notario público por autoridad apostólica y real, y por autoridad del arzobispo es notario de la escribanía de la curia del Vicariato de Tarragona, pero no consta que esté matriculado en el colegio de escritores. Firma también el acta del día 1 de septiembre de 1628 en los mismos términos, haciendo constar ahora que es notario de Tarragona y de la scribaniam publicam et communem dicte civitatis pro Illustrissimo Domino Archiepiscopo incluyendo, ahora sí, la condición de notario matriculado en el Archivo de la Curia. Joan Pau Oller está documentado en Tarragona actuando como notario entre 1609 y 1634, fechas extremas de los libros notariales que se conservan actualmente en el Archivo Histórico de Tarragona. Se trata de dos libros borradores (manualetum, según el sistema de redacción del documento notarial catalán)de 1220-1625 y 1633, un manual (1619-1620), un libro (1611-1625), un libro de capítulos matrimoniales

17. ASV, SCC, Rel. Dioc., 111-A.

18. ASV, SCC, Rel. Dioc., 399 A.

19. ASV, SCC, Rel. Dioc., 785 A-B.

20. ASV, SCC, Rel. Dioc., 291. 
(1609-1622), un libro de concordias y protestos(1634-1639) y un libro de procuras $(1612-1627)^{21}$.

Sin menospreciar los datos que ahora hemos citado nos detenemos en los libros de matrículas ya que son los que ofrecen más información sobre notarios catalanes hasta el año 1671, que es el último que hemos localizado, aunque el colegio siguió matriculando notarios extranjeros hasta el siglo XIX. Puesto que tanto Lesellier como San Martini exponen con todo detalle el funcionamiento del colegio y las características de la documentación, no nos detendremos ahora en estos aspectos. De hecho las cuestiones insertas en el presente trabajo y referidas al colegio de escritores del Archivo de la Curia están extraídas de los citados artículos. También algunos aspectos generales sobre el notariado en Roma han sido consultados en la última obra de Maria Luisa Lombardo ${ }^{22}$.

El análisis de los libros de matrícula nos proporciona datos interesantes y concluyentes sobre la presencia de notarios extranjeros en Roma a lo largo de los siglos modernos. En cada una de las matrículas se inserta el juramento individual de cada notario con las palabras escritas manu propria en cada uno de los registros. De cada uno de los notarios se dan el nombre y apellido, la procedencia (diócesis), el grado eclesiástico o la condición de laico, la autoridad pública por la que ejercen el oficio notarial, y el signum. Además de estos datos podemos observar dos cuestiones más. Por un lado lo referente a los aspectos gráficos, donde vemos notables diferencias en la escritura utilizada en las diversas regiones de la Europa católica. Los notarios procedentes de la Corona de Aragón presentan una grafía con unas marcadas características humanísticas que no encontramos en la escritura de los notarios castellanos, que presenta un trazado gótico cursivo propio de la época. Por otro lado se observan diferencias en los signa notariorum de los notarios de los países mediterráneos respecto los de países del centro y norte de Europa, división que viene dada por las diferencias marcadas entre los que pertenecen al ámbito notarial latino y los de otras tradiciones.

En estos libros se insertan las fórmulas de juramento de los notarios que se matriculan y siguen siempre un modelo establecido y que encontramos en el primer libro de registro ${ }^{23}$. Antes de dicha fórmula se inserta el proceso por el que eran interrogados los candidatos a notario, con un orden establecido-Ordo modus creandi notarius in archivio- y un ritual muy propio del ámbito donde se produce. El candidato se situaba delante de uno de los correctores del archivo y, de rodillas pronuncia unas palabras solicitando el oficio del notariado: Reverendi patres et domini mei supplico ut ille dignetur, auctoritate apostolica, creare me notarius et iudicem ordinarium in foma solita et consueta. Posteriormente era examinado super moribus, super etate, super gramatica, si scit bene scribere, si habet aliqua practica. Después se le nombraba notario público mediante la entrega de

21. I. COMPANYS I FARRERONS. Catàleg dels protocols notarials de Tarragona (14721899), Barcelona: Fundació Noguera, 2000, pp. 178-179.

22. M.L. LOMBARDO. Il notaio romano tra sovranità pontificia e autonomia comunale (Secoli XIV-XVI), Milano: Giuffrè Ed., 2012.

23. ASV, Santini, 23, f. f. 238-238v. 
una pluma, un tintero y un papel, como símbolos del nuevo oficio. El candidato juraba entonces y finalizaba el acto cuando Deinde creatus scribat iuramentum suum manu propria cum signo more aliroum in hoc libro vel alio ubi notabunt matricula, et unus ex dominis scriptoribus qui rogatus de Actus rogatus scribat nomen suum in marginem. Este ritual y la fórmula de creación de notarios lo encontramos también en un formulario conservado en el mismo fondo documental que los libros de matrícula. Se trata de un libro tamaño folio fechado en el primer tercio del siglo XVI. Incluye fórmulas diversas de creación de notarios atendiendo a una variada casuística que contempla, por ejemplo, la creación de notarios en ausencia $^{24}$. Esta fórmula y el sistema de nombramiento de notarios sigue el mismo patrón en los libros de registro de las matrículas, con variaciones puntuales, pero conservando la esencia.

En los libros de matriculación localizamos un total de 73 notarios procedentes de las diócesis catalanas ${ }^{25}$. Así lo indican los diferentes juramentos que se han consultado. El grupo más numeroso es el de los notarios de Girona y en último lugar están los de Tortosa, Urgell y Vic, con cinco notarios cada diócesis. Solamente en el caso del clérigo Miquel Vidal no consta la procedencia, aunque se dice que viene de la Torre de Claramunt, parroquia que pertenece a la diócesis de Barcelona ${ }^{26}$.

Tabla 1: Diócesis de procedencia

\begin{tabular}{|l|l|}
\hline Barcelona & 11 \\
\hline Girona & 23 \\
\hline Lleida & 15 \\
\hline Tarragona & 8 \\
\hline Tortosa & 5 \\
\hline Urgell & 5 \\
\hline Vic & 5 \\
\hline no consta & 1 \\
\hline Total & $\mathbf{7 3}$ \\
\hline
\end{tabular}

A la vista de los datos objetivos de la tabla no podemos llegar a conclusiones sobre la diferencia entre diócesis. Tal vez sorprenda que Tarragona, capital metropolitana y primada no destaque por la aportación de notarios a la Curia y a la Urbe y, en cambio, sí lo haga Girona, una sede menos importante que la tarraconense.

Otro dato insertado en las fórmulas es la autoridad por la que ejercen el oficio notarial en su lugar de procedencia.

24. ASV, Santini 228. Formulario per il Collegio degli Scrittori dell'Archivio della Curia Romana (in pergamena).

25. Apéndice I. Lista de notarios.

26. Apéndice I, n. 69. 
Tabla 2: Autoridad del oficio notarial

\begin{tabular}{|l|l|}
\hline autoridad apostólica & 48 \\
\hline autoridad apostólica e imperial & 6 \\
\hline autoridad apostólica y real & 3 \\
\hline autoridad real & 1 \\
\hline no consta & 15 \\
\hline Total & $\mathbf{7 3}$ \\
\hline
\end{tabular}

Los datos nos ayudan a concluir que más de la mitad de los notarios catalanes matriculados en la Curia lo son por autoridad apostólica. Y en nueve casos comparten, además, con la imperial y la real. Se trata pues de notarios apostólicos que llegan a Roma con la voluntad de integrarse en la Curia o de trabajar como fedatarios públicos en la ciudad, tal como figura en los juramentos: promitto officium meum notariatus in urbe et ubique locorum exercere. En los quince casos en los que no consta la autoridad no sabemos a qué es debido. En cualquier caso se trata siempre de clérigos, excepto el caso de Miquel Valent, laico de Vic ${ }^{27}$. También se da otra particularidad en un notario de Girona, de quien no consta el grado eclesiástico o la condición laical ni tampoco consta la autoridad por la que ejerce. Se trata de Joan Roca y su juramento no dice que sea notario público. Únicamente anota que es del lugar de Parlavà, en la diócesis de Girona ${ }^{28}$. Los restantes clérigos en los que no consta la autoridad son 4 de Lleida, 2 de Tarragona, 1 de Barcelona y 6 de Girona. Tal vez podríamos aventurar que se trate de notarios que ejercían esta función en las numerosas parroquias catalanas que tenían adscrita una notaría de su propiedad ${ }^{29}$. Estos notarios, al llegar a la ciudad por los motivos que fueran, querían ejercer su función tal como hacían en su lugar de origen, y tenían que pasar por los mismos requisitos que los demás, pero lógicamente no constaba ninguna autoridad que les hubiera conferido la función notarial. En sus lugares de origen, y tal como hacían constar en las suscripciones en los instrumentos redactados in mundum anotaban que eran notarios por el rector, que a su vez también era notario además de párroco.

Finalmente, otro dato que aparece en los juramentos es la condición de eclesiásticos o laicos, o algún grado académico.

27. Apéndice I, n. 72.

28. Apéndice I, n. 70.

29. D. PIÑOL ALABART. El notariat públic al Camp de Tarragona. Història, acrivitat, escriptura i societat (segles XIII-XIV), Barcelona: Fundación Noguera, 2000, pp. 117-138. R. GINEBRA. "Les escrivanies eclesiàstiques a Catalunya", en Actes del II Congrés d'Història del Notariat Català, Barcelona:Fundació Noguera, 2000, pp. 89-160. 
Tabla 3: Condición de los notarios

\begin{tabular}{|l|l|}
\hline bachiller en los dos derechos & 1 \\
\hline clérigo & 64 \\
\hline clérigo y bachiller en decretos & 1 \\
\hline fraile & 1 \\
\hline laico & 1 \\
\hline no consta & 1 \\
\hline presbítero & 4 \\
\hline Total & $\mathbf{7 3}$ \\
\hline
\end{tabular}

Como se observa en la tabla n. 3 la inmensa mayoría de notarios matriculados son clérigos. Estos coinciden con los datos de la tabla n. 2 ya que la mayoría de los clérigos y presbíteros son notarios por autoridad apostólica. El único laico matriculado no hace constar la autoridad, como se ha apuntado más arriba. Tampoco hace constar esta autoridad el fraile tarraconense Ramon $\mathrm{Bru}^{30}$, seguramente porque los miembros de órdenes religiosas no ejercían en ningún momento como notarios por carecer del encargo de la cura de almas ni la regencia de una parroquia, al menos en la diócesis de Tarragona de la que procede. Tampoco nos dice a qué orden religiosa pertenece.

\section{LOS SIGNOS NOTARIALES}

En la fórmula de juramento y creación de notario se insertan los signos notariales de cada uno de los notarios matriculados. En referencia a los signa debemos decir que, en principio, se sigue la estética del signum que vemos en los documentos redactados en pergamino en cualquier notaría catalana de los siglos XVI y XVII. Ahora bien, en muchos casos se detectan elementos que los hacen diferentes y uno de los que destacan por encima de todos es la presencia de las dos llaves cruzadas sobre las que se inscribe el resto de la rúbrica. Ya sea con líneas más estilizadas o más o menos bien dibujadas, incluso con cordones que recuerdan ligeramente el escudo pontificio, las llaves aparecen en 39 signos. No podemos concluir de que se trate siempre de notarios apostólicos los que insertan las llaves pontificias en sus signa ya que algunos que no lo son sí que las insertan. También muchos signos notariales incluyen una cruz en la parte superior, de pequeño tamaño y con formas diversas. Abunda, no obstante, la cruz latina con los brazos rematados con bolas o también la cruz latina potenzada.

Otra característica es la presencia de divisas en 21 casos. Se trata de frases que aparecen inscritas dentro de filacterias, cartelas o en el espacio inferior de una pirámide escalonada sobre la que se asienta el conjunto del signo. Esta pirámide tiene entre 1 y 6 escalones, y en algunas ocasiones aparecen decorados con líneas

30. Apéndice I, n. 73. 
a modo de sillería, o con otros elementos decorativos. Las divisas son de diversa índole, y pertenecen a textos religiosos, jurídicos o literarios. Algunas se han podido identificar, sobre todo las procedentes de textos bíblicos: A domino factum est istud (Salmo 118, 23) ${ }^{31}$; Domine adiubame (salmo 70, 6) ${ }^{32}$; In Domino sperans, non infirmabor (salmo 26, 1) ${ }^{33}$; In Domino confido (salmo 11, 1) ${ }^{34}$; Via, veritas, vite (Jn 14, 6) $)^{35}$; Soli Deo honor (1 Tm 1, 17) ${ }^{36}$. Fácil de identificar es la divisa Hoc signo vinces, que aparece en el signo de Gabriel Carbonell, ya citado, y en el de Francesc d'Altarriba, frase que se refiere a la victoria del emperador Constantino en el puente Milvio contra Majencio.

También dentro de las frases religiosas podemos incluir Deo perpetuam cognosse ${ }^{37}$; Uncola Deum ${ }^{38}$; Hinc Deum ${ }^{39}$; Deo favente ${ }^{40}$, que alude al favor de Dios.

Otras frases hacen referencia a la correcta moral en el desarrollo de la función notarial, primando la verdad por encima de todo: Veritas vincit ${ }^{41}$; legalitas ${ }^{42}$; Invidia repulsa ${ }^{43}$; Veritas est servanda ${ }^{44}$. Finalmente otras frases que no hemos podido identificar, algunas por ser ilegibles, son Missus satis sibi ${ }^{45}$, Finis est cuius omnia finint $^{46}$; (...)osse te ipsum ${ }^{47}$; Erunc tavit ${ }^{48}$. En el signum de Andreu Botella aparece las siglas $S q d$ situadas en el interior de un triángulo invertido, pero no sabemos su significado y es evidente que no guardan relación con el nombre del notario.

En 13 ocasiones encontramos el nombre del notario alrededor del signo o con las siglas del nombre insertas en él. También aparece el anagrama de Jesucristo (JHS) en el interior de dos signos, y algunos elementos especiales que aluden a los apellidos de los notarios que los diseñan y usan. Así tenemos una cepa (rabassa, en catalán) con las llaves de San Pedro, la cruz en la parte superior y la leyenda veritas vincit en la parte inferior, dentro de un tronco a modo de raíz en el signo de Pere Rabassa; un castillo, también con las llaves y la cruz en el signo de Antoni Castelló; un corazón acompañado de las llaves y dos $S$ a ambos lados de la figura central en el signo de Pere Cordesses; finalmente destacamos un reloj de arena en el signum de Miquel Valent, signo que está impreso como acostumbra a ser habit-

31. Apéndice II, n. 33.

32. Apéndice II, n. 40.

33. Apéndice II, n. 51.

34. Apéndice II, n. 69.

35. Apéndice II, n. 66.

36. Apéndice II, n. 71.

37. Apéndice II, n. 2.

38. Apéndice II, n. 31.

39. Apéndice II, n. 50.

40. Apéndice II, n. 60.

41. Apéndice II, n. 19.

42. Apéndice II, n. 29.

43. Apéndice II, n. 55.

44. Apéndice II, n. 41.

45. Apéndice II, n. 28.

46. Apéndice II, n. 44.

47. Apéndice II, n. 53.

48. Apéndice II, n. 56. 
ual en muchos notarios a partir de mediados del siglo XVII ${ }^{49}$. Este signo contiene una cartela en la parte inferior con la divisa sic vita fluit y alude a la moda barroca del paso del tiempo, de la fugacidad de la vida y de la presencia incómoda y persistente de la muerte ${ }^{50}$.

En el signo del notario Gabriel Carbonell, de Tarragona, aparece un rombo con la letra Tau inserta dentro de él, las llaves pontificias y una cruz en la parte superior, y una filacteria con la leyenda constantiniana hoc signo vinces en la parte inferior $^{51}$. Este notario quiso insertar en su signo notarial el emblema propio de su diócesis de origen. De hecho la letra Tau era el emblema heráldico de la sede metropolitana de Tarragona y se insertó en los signos notariales de los notarios nombrados por el arzobispo para regentar la escribanía pública de la ciudad, propiedad del metropolitano. Desde 1291 con el notario Miquel Bote todos los notarios tarraconenses que tenían la regencia de esta escribanía utilizaron el mismo signum aunque con variaciones personales pero siempre con la Tau como elemento cen$\operatorname{tral}^{52}$. En cambio no la utilizaron los otros notarios que trabajaban en otras oficinas notariales tarraconenses (escribanía municipal, escribanías de las veguerías real y arzobispal, escribanía del Oficial...).

\section{LA ACTIVIDAD DE LOS NOTARIOS CATALANES EN ROMA}

La pregunta que surge una vez que ya conocemos a los notarios es: ¿Estos notarios lograban trabajar en una oficina notarial en Roma o únicamente ejercían su oficio dentro de alguna de las oficinas curiales?. Si ejercían su oficio ¿se conservan los registros notariales fruto de su actividad? Y aún más: ¿quién acudía a estas notarías?; ¿eran miembros del colectivo de catalanes que vivían en la ciudad?.

La primera cuestión tiene fácil respuesta. Si la matrícula era obligatoria para ejercer en Roma, es lógico que, si aparecen matriculados, era por alguna razón. Ciertamente que debemos pensar que algunos notarios catalanes permanecían en la ciudad trabajando como tales en alguna notaría pública. Dandelet cita a los notarios Alonso de Ávila y Jerónimo Rabassa, que trabajaron en la ciudad y redactaron documentación notarial conservada en el Archivio Storico Capitolino ${ }^{53}$. Avila tiene su actividad entre los años 1562 y 1586 , muere en 1604 y deja como

49. Apéndice II, n. 72 .

50. M. VOVELLE. La morte e l'Occidente. Dal 1300 ai giorni nostri, Roma-Bari: Ed. Laterza, 2000, pp. 206-209.

51. Apéndice II, n. 3.

52. S. RAMON, F.X. RICOMÀ. (eds.) Índex Vell. Índex dels documents de l'Arxiu de l'Arquebisbe, 1679, Tarragona: Publicacions de la Diputació de Tarragona, 1997, pp. 57-58 (1291, octubre, 22): "Ítem una ordinació fea per lo archebisbe don Rodrigo en què manà a Miquel Boter, notari públich de Tarragona, que en tots los actes que autenticaria ell o altri per ell haguessen de fer lo senyal de Santa Tecla en esta forma de Ty vol que la guardeu també sos successors en dit offici (...)”. J.M. RECASENS. La ciutat de Tarragona, vol.2, Barcelona: Ed. Barcino, 1975, pp. 174-175.

53. Th.LANDELET. La Roma...., pp. 187-193. 
fruto de su actividad un total de 20 volúmenes $^{54}$. Parece ser que Jerónimo Rabassa retomó los negocios del primero a partir de 1586. Rabassa, que era notario apostólico valenciano, inicia su actividad en 1576 y se conserva documentación hasta 1593. Dandelet no cita la documentación de este otro notario pero la hemos localizado también en el Archivio Storico Capitolino ${ }^{55}$. Toda esta documentación sirve para conocer las actividades de los grupos de comerciantes españoles en general y catalanes en particular que se instalan en Roma en el siglo XVI. Estos comerciantes, junto con otros profesionales y también notarios, forman la clase media procedente de los reinos hispánicos que vive en Roma y que acude a estos notarios para realizar sus contratos jurídicos. Es lógico que cada nación acuda a los notarios que proceden de ella misma ${ }^{56}$.

A partir de estas consideraciones iniciales debemos abordar la segunda cuestión referida a los registros notariales conservados. Lesellier, que también se formula preguntas parecidas, alude al laberinto que supone la investigación con los registros notariales producidos por los notarios romanos y hemos constatado esta realidad $^{57}$. Por un lado es patente la dispersión de la documentación notarial entre el Archivio di Stato de Roma y el Archivio Storico Capitolino. Pero, una vez llegamos a cada archivo topamos con la problemática de los instrumentos de descripción.

El problema de la dispersión de los registros notariales no es nuevo. Ya en época moderna se quiso solucionar esta situación con la creación de un nuevo archivo. El papa Urbano VIII, con la bula Pastoralis officii del 16 de noviembre de 1625, creó el Archivio Urbano que recogiera todos los registros generados en Roma $^{58}$. Este Archivo se conserva actualmente en el Archivio Storico Capitolino y en él localizamos algunos registros notariales redactados por los notarios catalanes matriculados en el Colegio.

En el Archivio di Stato de Roma se conservan registros notariales generados por notarios principalmente romanos aunque también podemos encontrar fedatarios extranjeros. Las fechas de los registros van del siglo XIV a los primeros decenios del XVII ${ }^{59}$. Orieta Verdi apunta que hay que acudir al Elenco publicado

54. M.L. SAN MARTINI BARROVECCHIO. "Il colegio...", pp. 871. Lo cita en la lista de notarios escritores del Colegio del Archivo de la Curia.

55. ASC, AU, n. 605.

56. Sobre esta cuestión vid. A. ESPOSITO. "Roma e i suoi notai: Le diverse realtà di una città capitale (fine sec. XIV-inizio sec. XVI)", en V. PIERGIOVANNI. (ed.) Il notaio e la città: essere notaio: $i$ tempi e i luoghi, sec. XII-XV, Milano: Giuffrè Ed., 2009, pp. 93-111.

57. J. LESELLIER. "Notaires...”, pp. 250; 265-275. Para conocer un poco la situación de la documentación notarial en Roma es preciso también leer las diferentes introducciones que se insertan en los nuevos instrumentos de descripción de los archivos.

58. A.M. CORBO. "Relazione descrittiva degli archivi notarili Romani dei secoli XIV-XV nell'Archivio di Stato e nell'Archivio Capitolino", en P. BREZZI, E. LEE. (coord.) Gli atti privati nel tardo medioevo: fonti per la storia sociale, Roma: Istituto di Studi Romani, 1984, pp. 49-67.

59. O. VERDI. "L'Archivio del Collegio dei notai capitolini (1348-1628)", en R. DE VIZIO. (coord.) Repertorio dei notari romani dal 1348 al 1927, dall' 'Elenco' di Achille François, Roma: Fondazione Marco Besso, 2011, pp. XXV-XXXII. 
en $1886^{60}$, con todas las limitaciones que tiene, para poder localizar la documentación. Con el proyecto iniciado en el año 2005 se pretende revisar la descripción, llegando también a la informatización y digitalización de algunos documentos. Consultando la página web del Archivio di Stato llegamos a algunos instrumentos de búsqueda ya informatizados, pero entre éstos no se encuentran, por el momento, los correspondientes a los notarios capitolinos.

En el Archivio di Stato debemos acudir a los inventarios 8 y 9 y localizamos documentación referente a Gabriel Arerols (libro 1914, n. 372, 1518), Baldiri Avinyó (libro 1908, n. 91, 1521), Jaume Corts (libro 1914, n. 115, 1515), Jaume Jutglar (libro 1914, n. 448, 1519), Bernat Simó (libro 1914, n. 9, 1503) y Joan Solsona (libro 1914, n. 273, año 1515). El problema de los instrumentos de descripción es que crean cierta confusión con los apellidos de los notarios, lo que hace que la búsqueda sea complicada $\mathrm{y}$, a veces, infructuosa. Por ejemplo podemos deducir que el notario que aparece citado como Gabriel Areolis se trata del notario que encontramos matriculado en el fondo Santini del Vaticano con el nombre Gabriel Arerols. Pero también aparece un Gabriel Aratoribus (años 1520-1522, n. 457, 556) y un Gabriel Arcolis (libro 1914, n. 372, año 1518). Este último sí lo es puesto que coincide en la fecha y en la signatura del documento con Gabriel Areolis, que es el primero que citamos aquí, y que tiene los mismos datos en la descripción. Baldiri Avinyó aparece citado en el inventario como Baldisius Anygnio. Viendo los datos que hemos introducido en el texto nos percatamos de que no se trata de registros completos si no de documentos que forman parte de volúmenes misceláneos. De hecho en estos volúmenes encontramos muchos más documentos pertenecientes a otros muchos notarios. Por lo tanto esta búsqueda no está cerrada y los datos que ofrecemos en este apartado son provisionales.

En el Archivio Storico Capitolino se conserva el Archivio Urbano, creado en $1625^{61}$. Básicamente los registros notariales que nos interesan se conservan en la sezione I que contiene 916 protocolos notariales de 1355 hasta 1725 . Son fechas, pues, que coinciden con las fechas de matriculación de los notarios catalanes. Algunos de los notarios de este archivo coinciden con los del Archivio di Stato, aunque los encontramos en diversos listados de notarios de esta misma sección. Algunos aparecen en un listado bajo la denominación Atti non sottoscritti dal notaio. La documentación localizada en esta sección pertenece a los notarios Baldiri Avinyó (n. 080, 1512); Gabriel Carbonell (n. 894, 1511); Jaume Corts (n. 434, 1509); Bernat Çaplana (n. 434, 1508); Francesc Gabriel (n. 483, 1590-1612); Jaume Jutglar (n. 894, 1516; n. 434, 1517-1518; n. 080, 1518-1527) ${ }^{62}$; Miquel Pardo de la Casa (n. 434, 1513), Jaume Puigçavall (n. 080, 1519); Pere Rabassa (n. 397.3, 1515-1521); Bernat Simó (n. 434, 1508; n. 894, 1508-1509); Joan Solsona (n. 434,

60. A. FRANÇOIS. Elenco di notari che rogarono atti in Roma dal secolo XIV all'anno 1886, Roma, 1886.

61. E. MORI. "L'Archivio Generale Urbano", en R. DE VIZIO. (coord.) Repertorio dei notari romani dal 1348 al 1927, dall' 'Elenco'di Achille François, Roma: Fondazione Marco Besso, 2011, pp. XXXIII-XLII.

62. En el índice del Archivo figura como Iacobus Inglar. 
1517-1518); Rafael Torrell (n. 761, 1551-1560). En este mismo fondo documental, en la sezione II, encontramos un listado con los Notai e scrittori dell'Archivio della Romana Curia (1507-1621) entre los que se conservan registros de Rafael Torrell (n. 38, 1553-1560,) y Francesc Segols (n. 42, 1562-1564; n. 51, 1566; n. 53, 1565 ; n. $58,1559-1561)^{63}$.

Los registros localizados en el Archivio Urbano siguen la misma tónica que los anteriores. Es decir, se trata de volúmenes misceláneos en los que se insertan instrumentos redactados por diversos notarios. Así lo comprobamos con la numeración de los documentos, que en algunos casos coinciden entre diversos notarios, variando únicamente los años de los instrumentos. Ahora bien, cuando accedemos a cada uno de los volúmenes observamos que no estamos únicamente ante documentos sueltos sino que nos encontramos ante registros con una cierta entidad, sobre todo en aquellos que localizamos a través del último listado, es decir, los de Rafael Torrell y Francesc Segols.

En el registro que figura con el número 53 no encontramos referencias al notario catalán Francesc Segols hasta el folio 339. El primer documento validado por este notario es del 15 de julio de 1565 y el último del 28 de diciembre de 1566. Lo mismo ocurre con el registro atribuido a Rafael Torrell, n. 38. No es hasta los folios 567-586 en que aparecen documentos redactados por éste, aunque entre estos folios encontramos instrumentos de otros fedatarios. El primer contrato es de 19 de febrero de 1555 y el último de 6 de octubre del mismo año. Y así sucede con los demás registros de estos y otros notarios.

Los documentos localizados son contratos de diversa índole y su estudio requiere un repaso más exhaustivo de cada uno de los protocolos notariales de manera que pudiéramos analizar la praxis y la actividad de estos fedatarios instalados en Roma. El primer instrumento redactado por uno de estos notarios es del 25 de mayo de 1508 y lo valida Bernat Simó ${ }^{64}$. Este notario se matriculó en el colegio el primero de abril de ese mismo año y en menos de un mes ya está trabajando como notario en la ciudad. El documento en cuestión es la ratificación que hizo en el año 1505 Guillermo Bertrán, protonotario apostólico procedente de la diócesis de Tuy, de la donación de una cuarta parte de un barco a dicha diócesis. En el documento se citan como procuradores del otorgante algunos eclesiásticos de la diócesis tudense. Pero el contrato no se firma en ninguna escribanía o notaría si no que se cierra in domo prefati domini Guillermi Bertrandi.

Son habituales los instrumentos en que aparecen algunos de los notarios que son objeto de este estudio. Así, el 22 de enero de 1518, el notario Gabriel Arerols, clericus Gerundensis dioecessm, publicus auctoritate apostolica notarius et in

63. Entre los instrumentos de descripción de los fondos notariales encontramos una introducción al Archivio Urbano. Sezione II - Notai e scrittori dell'Archivio della Romana Curia (1507-1621), a cura di C. FALUCCI, A. MARRONE, P. SANTONI. Coordinamento tecnico-scientifico: Elisabetta Mori. Roma, 2006. Se expone el proyecto de descripción de los fondos notariales con el que se pretende poder individualizar cada uno de los notarios dentro de cada volumen en la descripción, por lo que es posible que, más adelante podamos localizar más documentación de notarios catalanes.

64. ASR, CNC, 1914, n. 9. 
Archivio Romana Curia descriptus et matriculatus valida un documento referido a Baldiri Avinyó. Trata de las obligaciones que tiene este clérigo-notario con el beneficio de San Vicente de Valencia, que fue fundado por el difunto Gaspar Torroella, álias Gombau, difunto, miembro de la curia Romana ${ }^{65}$. Este tipo de noticias son habituales en los registros que hemos localizado. Haciendo una cata entre ellos se han encontrado, por ejemplo, diversas procuras. En éstas algunos eclesiásticos y también notarios de los notarios matriculados en el Archivo de la Curia y que se hallan presentes en Roma nombran procuradores a otros. En general los que son nombrados procuradores son también eclesiásticos y el cometido que deberán llevar a término es, sobre todo, cobrar rentas o cumplir con las obligaciones propias de los beneficios u otros oficios prebendados ${ }^{66}$. Por ejemplo, el notario Pere Rabassa -en los documentos localizados se intitula litterarum apostolicarum scriptor-, de Tarragona, nombra procuradores suyos a ciudadanos catalanes, la mayoría de ellos clérigos. La primera vez nombra a Jaume Alemany, caballero de Besalú, y a Francesc Agullana y Pere Juyà, clérigos de Girona ${ }^{67}$. Después nombra procuradores a Gabriel Arerols, clérigo y notario en Roma, a Julián Ferrer, clérigo de Girona, y Francesc Salgueda, clérigo de Barcelona ${ }^{68}$. Al cabo de unos días este mismo notario repite un nombramiento similar de Arerols y nombra también a Vicent Bassa, clérigo de Vic ${ }^{69}$. Y años más tarde vuelve a nombrar a Arerols como procurador, aunque esta vez solo a él ${ }^{70}$. Es solamente un pequeño ejemplo de la actividad notarial en Roma en el primer tercio del siglo XVI. Más adelante continúan los instrumentos similares en que los otorgantes son clérigos catalanes, algunos miembros de la Curia, laicos que viven en la capital y otorgan testamentos $^{71}$. $\mathrm{Y}$ en ocasiones se mezclan los instrumentos notariales con actas de las reuniones de la Cofradía de la Virgen de Montserrat ${ }^{72}$. Esta última evidencia es una muestra más de las características de esta documentación y de la dificultad que hay en afrontar su estudio, que requiere una atención más pormenorizada que la que hemos dedicado ahora. Además surge otra dificultad añadida que solamente se puede entender si nos adentramos en cada uno de los registros. Nos referimos a las fechas que aparecen en los instrumentos de descripción y que difieren de las que realmente aparecen en cada uno de los protocolos. Un ejemplo es el libro n. 58 de Francesc Segols, del que hemos sacado algunas noticias. Las fechas en el índice son 1559-1561 y, en cambio, encontramos contratos anteriores.

65. ASR, CNC, 1914, n. 37.

66. ASC, AU 47, f. 540. 1534, mayo, 21. Jaume Sunyer, clérigo de Urgell, nombra como procurador a Joan Soler, clérigo de la misma diócesis, para cobrar las rentas sobre la canónica de Guissona.

67. ASC, AU 47, f. 538. 1534, agosto, 7.

68. ASC, AU 47, f. 545. 1538, marzo, 4.

69. ASC, AU 47, f. 549. 1538, mayo, 2.

70. ASC, AU 47, f. 551. 1548, mayo, 10.

71. ASC, AU 55, f. 435-435v. 1544, mayo, 7. Testamento de Pere Ferran, laico de Girona, que dispone la sepultura en la iglesia de Montserrat en Roma.

72. ASC, AU 58. A lo largo del registro (años 1538-1541) se localizan diversas actas de las reuniones de la Cofradía, en las que aparecen nombres catalanes y algún clérigo. 
A la luz de estos datos, que no pretendemos que sean conclusivos como ya se ha dicho a raíz de otras evidencias, aún nos queda una pregunta por formular. ¿Estos notarios catalanes instalados en Roma, matriculados en el colegio de los escritores del Archivo de la Curia, eran los únicos notarios que vivían en la ciudad? Es evidente que no, puesto que en el mismo colegio aparecen los notarios que son miembros del mismo, entre los cuales aparece un clérigo catalán, Pere Vidal, de Tarragona, documentado entre 1533-1542 ${ }^{73}$. Y también encontraríamos notarios catalanes trabajando como protonotarios apostólicos, cuestión que dejamos para otra ocasión ${ }^{74}$.

Finalmente queremos formular otra pregunta. ¿Estos notarios que están en Roma, trabajaban ya como notarios en sus diócesis de origen? ¿Y, si volvían a sus notarías de origen, continuaban ejerciendo la función notarial?

Para responder a estas preguntas debemos repasar los instrumentos de descripción de los archivos notariales catalanes y ver la coincidencia de nombres y fechas, lo que nos lleva a encontrar algunos datos muy interesantes. De los notarios de la diócesis de Girona localizamos a Francesc Segols como escribiente de la notaría de Lladó y redactando un manual y un libro de los años 1552-1553, por lo tanto antes de matricularse en Roma en el año $1559^{75}$. También a Jaume Jutglar como notario de Vilabertran entre 1546 y $1553^{76}$, aunque por las fechas tenemos dudas de que se trate del notario matriculado en Roma en 1515.

De los notarios procedentes de la diócesis de Tarragona tenemos algunas noticias a destacar relacionadas con dos casos muy concretos ${ }^{77}$. Se trata de los clérigos Miquel Pardo de la $\mathrm{Casa}^{78}$ y de Francesc Carbonell ${ }^{79}$. De estos dos notarios hemos localizado protocolos notariales en el Archivo Histórico Archidiocesano de Tarragona que aportan más información sobre ambos. En el caso del primero aparece como rector de la parroquia de Santa María de Conesa en dos manuales notariales de la escribanía de dicha iglesia ${ }^{80}$. El primero contiene instrumentos entre el 8 de febrero de 1502 y el 28 de marzo de 1504. El segundo, con instrumentos entre el 8 de marzo de 1501 y el 19 de abril de 1514, está redactado por el notario Marius Florad, pero Miquel Pardo de la Casa consta como rector. El notario se intitula Marius Floraci, vicarium et notarium publicum de Conesa per discretum

73. M.L. SAN MARTINI BARROVECCHIO. “Il collegio...”, pp. 870. ASC, AU 58. f. 2. 1538, marzo, 27. Petrus Vidal, clericus Tarraconensis dioecesis, archivio romana curia scriptor, No dice que sea notario público si no, únicamente, que es miembro del colegio de escritores.

74. Hemos realizado diversas catas en los registros de Protonotarios Apostólicos entre los que se han localizado algunos catalanes.

75. M.A. ADROER, E. SERNA, S. SOLER. Catàleg dels protocols notarials del districte de Figueres (II), Barcelona: Fundació Noguera, 2004, p. 14 y p. 106. La notaría de Lladó fue arrendada el 1552 por el notario Baldiri Ceravosa a sus escribientes, entre ellos Francesc Segols.

76. IDEM, p. 442. Según los datos del catálogo solamente se conserva un manual de este notario.

77. S. RAMON I VINYES, M.M. FUENTES I GASÓ. Inventari dels protocols notarials de l'AHAT, Barcelona: Departament de Cultura de la Generalitat de Catalunya, 1987.

78. Apéndice I, n. 15.

79. Apéndice I, n. 32.

80. AHAT, Notaría Conesa, n. 15; n. 16. 
Micaelem Pardo de la Casa, rectore dicti loci ${ }^{81}$. En el mismo libro consta también Bartomeu Noet como rector porque el anterior, Pardo de la Casa, no aparece más entre los documentos. Sí que es cierto que se localiza en diversos instrumentos en los que nombra procuradores suyos e incluso, en el año 1504, nombra a Bartomeu Noet, beneficiado, como procurador suyo. Y Noet promete “...facere totam illam servitutem quam vos teneamini facere in dicta ecclesia de Conesia...”, durante un año ${ }^{82}$. Estos datos nos indican que este clérigo, rector de una pequeña parroquia rural, acude a Roma y se matricula como notario aunque no tenemos datos de que trabaje como notario público en la ciudad y parece que no vuelve a su lugar de origen. Al menos no lo localizamos más en tierras tarraconenses según lo que nos dicen los protocolos notariales. Otro caso similar es el de Francesc Carbonell puesto que localizamos un clérigo con el mismo nombre en la parroquia de Santa María de Tamarit entre los años 1530 y $1565^{83}$. En el primer libro es citado como rector de la parroquia y Pere Magrinyà, vicario y notario público por autoridad apostólica, es el regente de la escribanía pública y común por el rector. En estos manuales de Francesc Carbonell también constan como notarios Pere Berart, Antoni Monar, Antoni Duran, y Onofre Moix, eclesiásticos. La fecha del juramento de Carbonell en el colegio es el 1543, que coincide con uno de los manuales notariales conservados en Tarragona. Esta evidencia nos puede indicar que no se trata de la misma persona o, por el contrario, que sí es el mismo eclesiástico que llega a Roma ocasionalmente y vuelve después a su parroquia o delega la función rectora en otra persona. Pero en el libro n. 32 localizamos una noticia muy interesante redactada en catalán: Missa nova per Francesc Carbonell, natural de Rocafort de Queralt, l'any quatorze de sa possessió. Vingué molta gent y parents y feren gran festa y cantors y qüèstia de jutglars y grans balls, encara que fos la semana de Passió. Deus sibi acceptum reddat ${ }^{84}$. A la luz de estos datos parece ser que Francesc Carbonell tomó posesión de la parroquia de Tamarit el año 1537 pero no celebra la misa de entrada a la parroquia hasta el 1551 . No se ha localizado la fecha exacta de la toma de posesión ni tampoco sabemos si se hizo personalmente o a través de un procurador. Pero sí que dos años más tarde, en 1553, encontramos el nombre de este sacerdote como ...rector ecclesie castri de Tamarito, diocesis Tarracone, auctoritate apostolica notarius publicus et in Archivio Romane Curie descriptus.... Añade la fecha de matrícula, que coincide lógicamente con la que hemos localizado en el Archivo Vaticano, e inserta el signum que también coinci$\mathrm{de}^{85}$. Por lo tanto es una muestra de un notario catalán que, al volver a su lugar de origen, se incorpora a la escribanía y pasa a regentarla él mismo y no delegando en otros. Y lo hace porque ahora es notario cuando antes de ir a Roma solamente era el rector de la parroquia.

81. AHAT, Notaría Conesa, 16, 1501-1514. Portada.

82. AHAT, Notaría de Conesa, 15, s.f. 1504, marzo, 28.

83. AHAT, Notaría Tamarit, n. 30 (1530-1538); n. 32 (1549-1551); n. 33 (1542-1555); n. 34 (1561-1563); n. 35 (1563-1565).

84. AHAT, Notaría Tamarit, n. 32, f. 68. 1551, marzo, 25.

85. AHAT, Notaría Tamarit, n. 33, f. 22. 1552, junio, 17. 
Del mismo tenor localizamos al notario vigatense Jeroni Montargull, matriculado en Roma el 1552, que firma un instrumento como rector del Castillo de Montornés, en la diócesis de Vic, y como notario público por autoridad apostólica e imperial y matriculado en el Archivo de la Curia Romana. El instrumento es una venta de censal del año $1578^{86}$, y la suscripción notarial nos da muestras de que el notario, una vez que volvió de Roma, se incorporó como presbítero a la cura animarum y a ejercer como notario, con toda la autoridad que el haber estado en Roma le confería a su oficio. No obstante no sabemos si ya antes ejercía de notario, de rector, o de ambas cosas a la vez, o de ninguna. De hecho en la fórmula de juramento indica que es clérigo y notario público por autoridad apostólica e imperial ${ }^{87}$.

86. AHT, Pergamins Sta. Coloma, 1/487. 1578, diciembre, 10. Se ha podido localizar este pergamino gracias al catálogo de esta colección que realizamos hace unos años y que está a disposición de los investigadores en el Archivo Histórico de Tarragona. El catálogo incorpora un estudio introductorio y un índice antroponímico y toponímico que nos ha permitido encontrar al notario Montargull. La mayor parte de estos pergaminos proceden de la notaría parroquial de Santa Coloma de Queralt, que pertenecía a la diócesis de Vic y que a mediados del siglo XX pasó a la diócesis de Tarragona.

87. Apéndice I, n. 52. 


\begin{tabular}{|c|c|c|c|c|c|c|}
\hline $\mathbf{N}$. & Referencia & Fecha & Nombre & Condición del notario & Autoridad & Diócesis \\
\hline 1 & ASV, Santini 23, f. 14v. & $14 / 01 / 1508$ & Serra, Jaume & clérigo & apostólica & Tortosa \\
\hline 2 & ASV, Santini 23, f. 19 & $28 / 01 / 1508$ & Çaplana, Bernat & clérigo & apostólica & Girona \\
\hline 3 & ASV, Santini 23 , f. 30v. & $15 / 03 / 1508$ & Gabriel Carbonell & clérigo & apostólica e imperial & Tarragona \\
\hline 4 & ASV, Santini 23, f. 30v. & $15 / 03 / 1508$ & Hortoneda, Pere & clérigo y bachiller en decretos & apostólica e imperial & Urgell \\
\hline 5 & ASV, Santini 23, f. 46. & $01 / 04 / 1508$ & Colldesanta, Pere & clérigo & apostólica & Barcelona \\
\hline 6 & ASV, Santini 23, f. 33 & $01 / 04 / 1508$ & Simó, Bernat & bachiller en dos derechos & apostólica & Tarragona \\
\hline 7 & ASV, Santini 23, f. 49v. & $11 / 10 / 1508$ & Corts, Jaume & presbítero & apostólica & Girona \\
\hline 8 & ASV, Santini 23 , f. $63 \mathrm{v}$. & $21 / 05 / 1509$ & Maria, Antoni & clérigo & apostólica e imperial & Vic \\
\hline 9 & ASV, Santini, 23, f. 66 & $11 / 06 / 1509$ & Joan Saganta, Berenguer & clérigo & apostólica & Lleida \\
\hline 10 & ASV, Santini 23, f. 83v. & 05/04/1510 & Prat, Segimon de & clérigo & apostólica y real & Girona \\
\hline 11 & ASV, Santini 23, f. 102. & $01 / 09 / 1511$ & Costa, Bartomeu & clérigo & apostólica e imperial & Lleida \\
\hline 12 & ASV, Santini 23, f. 106v & $15 / 11 / 1511$ & Llorenç, Pere & clérigo & apostólica & Girona \\
\hline 13 & ASV, Santini 23, f. 109. & $16 / 12 / 1511$ & Vaya, Joan & clérigo & apostólica & Barcelona \\
\hline 14 & ASV, Santini 23, f. 110. & $22 / 01 / 1512$ & Avinyó, Baldiri & clérigo & apostólica & Girona \\
\hline 15 & ASV, Santini 23, f. 123. & $01 / 12 / 1512$ & Pardo de la Casa, Miquel & clérigo & apostólica & Tarragona \\
\hline 16 & ASV, Santini 23, f. 123v & 20/12/1512 & Solsona, Joan & clérigo & apostólica & Barcelona \\
\hline
\end{tabular}




\begin{tabular}{|c|c|c|c|c|c|c|}
\hline N. & Referencia & Fecha & Nombre & Condición del notario & Autoridad & Diócesis \\
\hline 17 & ASV, Santini 23, f. 139v & $01 / 01 / 1514$ & Arerols, Gabriel & clérigo & apostólica & Girona \\
\hline 18 & ASV, Santini 23, f. 170 & $24 / 08 / 1515$ & Llobet, Pere & presbítero & no consta & Girona \\
\hline 19 & ASV, Santini 23, f. 174 & $03 / 11 / 1515$ & Rabassa, Pere & clérigo & no consta & Tarragona \\
\hline 20 & ASV, Santini 23, f. 176v. & $03 / 12 / 1515$ & Botella, Andreu & clérigo & apostólica & Lleida \\
\hline 21 & ASV, Santini 23, f. 177 & $03 / 12 / 1515$ & Jutglar, Jaume & clérigo & apostólica & Girona \\
\hline 22 & ASV, Santini 23, f. 208 & $14 / 12 / 1517$ & Puig, Jaume & clérigo & real & Tarragona \\
\hline 23 & ASV, Santini 23, f. 236 & 01/01/1519 & Puig Çavall, Jaume & clérigo & apostólica & Barcelona \\
\hline 24 & ASV, Santini 23, f. 230v. & $23 / 03 / 1519$ & Rossell, Vicenç & clérigo & apostólica & Barcelona \\
\hline 25 & ASV, Santini 23, f. 231 & 06/04/1519 & Guiu, Jaume & clérigo & apostólica & Vic \\
\hline 26 & ASV, Santini 23, f. 232 & $18 / 04 / 1519$ & Carbonell, Jeroni & clérigo & apostólica y real & Tarragona \\
\hline 27 & ASV, Santini 24, f. 2 & $29 / 07 / 1539$ & Cornell, Miquel & clérigo & apostólica & Lleida \\
\hline 28 & ASV, Santini 24, f. 6 & $07 / 02 / 1540$ & Pertusa, Esteve & clérigo & apostólica & Lleida \\
\hline 29 & ASV, Santini 24, f. 26 & $17 / 02 / 1542$ & Prats, Esteve & clérigo & apostólica & Barcelona \\
\hline 30 & ASV, Santini 24, f. 44 & $05 / 09 / 1543$ & Pérez, Francesc Joan & clérigo & apostólica & Tortosa \\
\hline 31 & ASV, Santini 24 , f. $45 \mathrm{v}$. & $18 / 10 / 1543$ & Pagès, Pere & clérigo & apostólica & Girona \\
\hline 32 & ASV, Santini 24, f. 36 & $29 / 12 / 1543$ & Carbonell, Francesc & clérigo & apostólica & Tarragona \\
\hline 33 & ASV, Santini 24, f. 59 & $08 / 03 / 1545$ & Urgellès, Antoni & clérigo & apostólica & Lleida \\
\hline
\end{tabular}




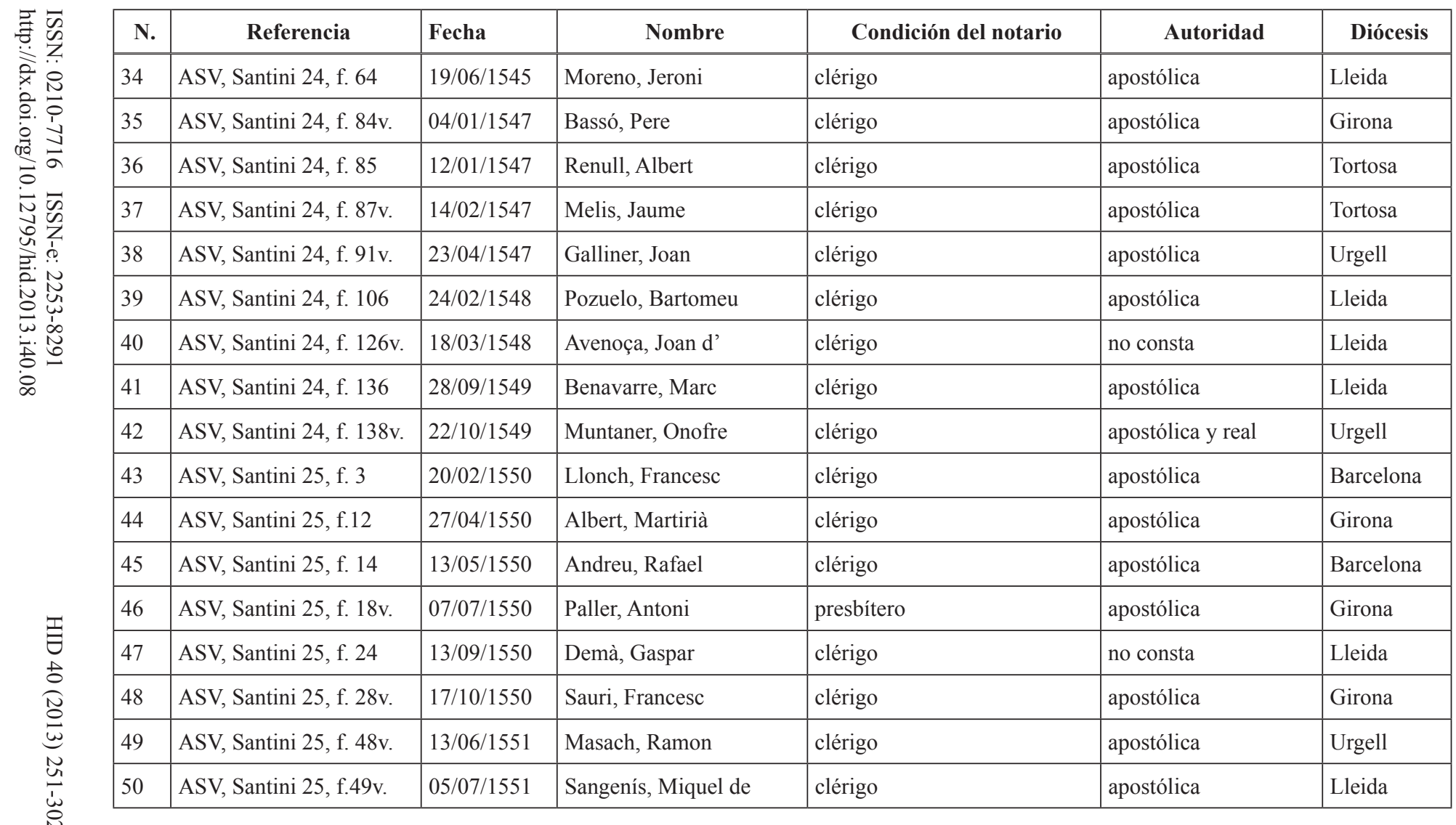




\begin{tabular}{|c|c|c|c|c|c|c|}
\hline N. & Referencia & Fecha & Nombre & Condición del notario & Autoridad & Diócesis \\
\hline 51 & ASV, Santini 25, f. 53v. & 20/11/1551 & Torrell, Rafael & clérigo & apostólica & Barcelona \\
\hline 52 & ASV, Santini 25, f. 59 & $14 / 02 / 1552$ & Montargull, Jeroni & clérigo & apostólica e imperial & Vic \\
\hline 53 & ASV, Santini 25, f. 60 & $21 / 03 / 1552$ & Iscla Moy, Pere & clérigo & apostólica e imperial & Girona \\
\hline 54 & ASV, Santini 25, f. 70v. & $23 / 09 / 1552$ & Randoní, Nicolau & clérigo & apostólica & Vic \\
\hline 55 & ASV, Santini 25, f. 131 & $07 / 10 / 1555$ & Castelló, Antoni & clérigo & apostólica & Girona \\
\hline 56 & ASV, Santini 25, f. 131 & $07 / 10 / 1555$ & Cordesses, Pere & clérigo & apostólica & Girona \\
\hline 57 & ASV, Santini 25 , f. 140v. & $11 / 04 / 1556$ & Alemany, Pau Antoni d' & clérigo & apostólica & Girona \\
\hline 58 & ASV, Santini 25, f. 171v. & $03 / 01 / 1558$ & Altarriba, Francesc d' & clérigo & apostólica & Lleida \\
\hline 59 & ASV, Santini 25 , f. $187 \mathrm{v}$. & $01 / 02 / 1559$ & Segols, Francesc & clérigo & no consta & Girona \\
\hline 60 & ASV, Santini 25, f. 196 & $26 / 10 / 1559$ & Calassanç, Jeroni & clérigo & apostólica & Lleida \\
\hline 61 & ASV, Santini 25, f. 208v. & $01 / 08 / 1560$ & Gallifa, Pere & presbítero & no consta & Urgell \\
\hline 62 & ASV, Santini 26, f. 7 & $09 / 09 / 1577$ & Casaus, Sebastià & clérigo & no consta & Girona \\
\hline 63 & ASV, Santini 26, f. $7 v$. & $09 / 09 / 1577$ & Llevanera, Montserrat & clérigo & no consta & Girona \\
\hline 64 & ASV, Santini 26, f. 14 & $24 / 01 / 1578$ & Miró, Guillem & clérigo & no consta & Girona \\
\hline 65 & ASV, Santini 26, f. 31 & $10 / 03 / 1579$ & Vahí, Narcís & clérigo & no consta & Girona \\
\hline 66 & ASV, Santini 26, f. 62 & $12 / 01 / 1580$ & Ginestar, Miquel & clérigo & no consta & Barcelona \\
\hline 67 & ASV, Santini 26, f. 59v. & $20 / 06 / 1580$ & Colomer, Antoni & clérigo & no consta & Tortosa \\
\hline
\end{tabular}




\begin{tabular}{|c|c|c|c|c|c|c|}
\hline N. & Referencia & Fecha & Nombre & Condición del notario & Autoridad & Diócesis \\
\hline 69 & ASV, Santini 26, f. 104 & $23 / 02 / 1583$ & Vidal, Miquel & clérigo & no consta & no consta \\
\hline 70 & ASV, Santini 26, f. 113 & $16 / 07 / 1583$ & Roca, Joan & no consta & apostólica & Girona \\
\hline 71 & ASV, Santini 26, f. 132v. & $28 / 01 / 1585$ & Feu, Pere & clérigo & no consta & Barcelona \\
\hline
\end{tabular}


APÉNDICE II: SIGNOS NOTARIALES

Serra, Jaume Nombre




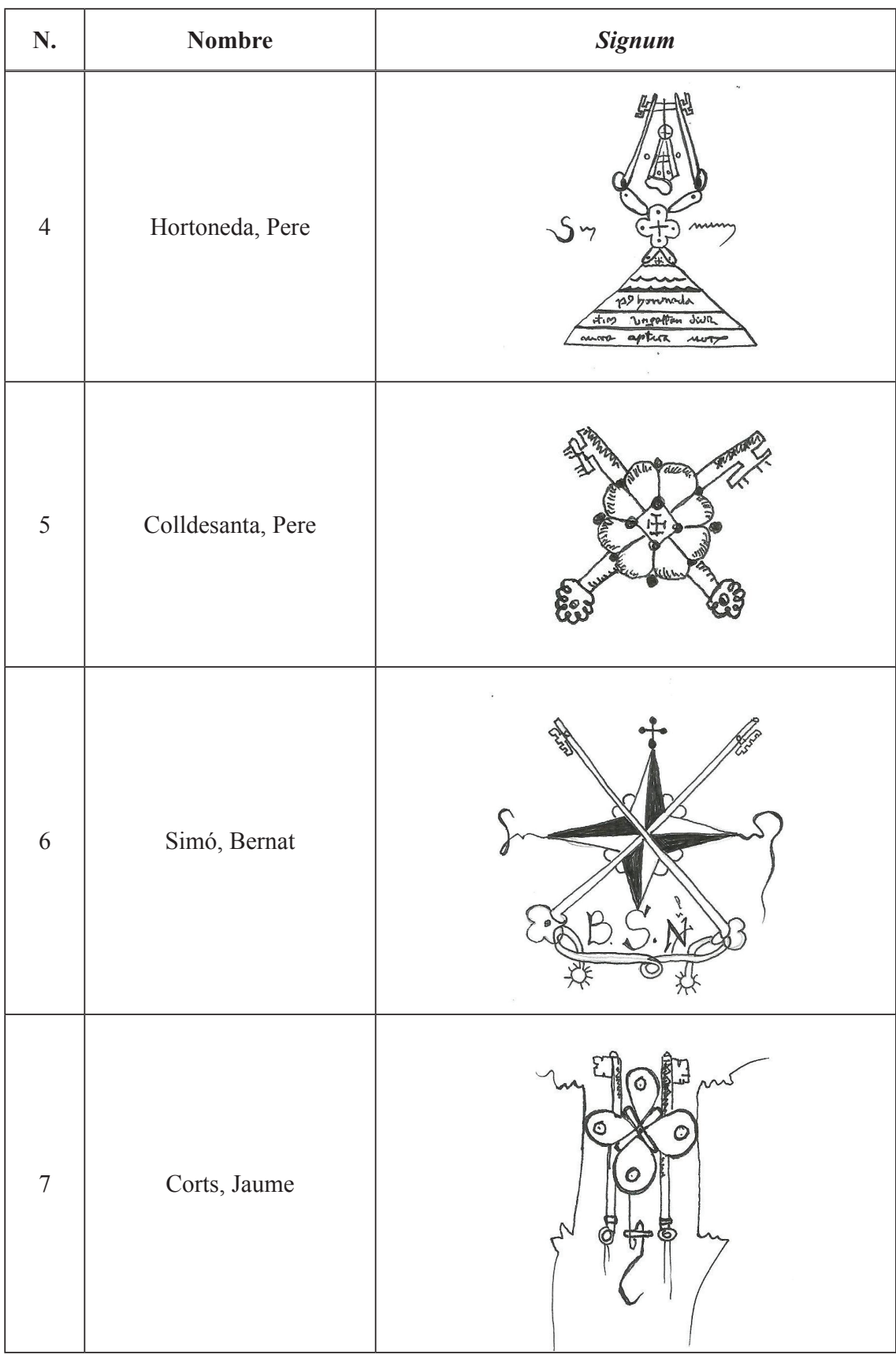




Maria, Antoni




Costa, Bartomeu




Nombre




N. 1 Nombre




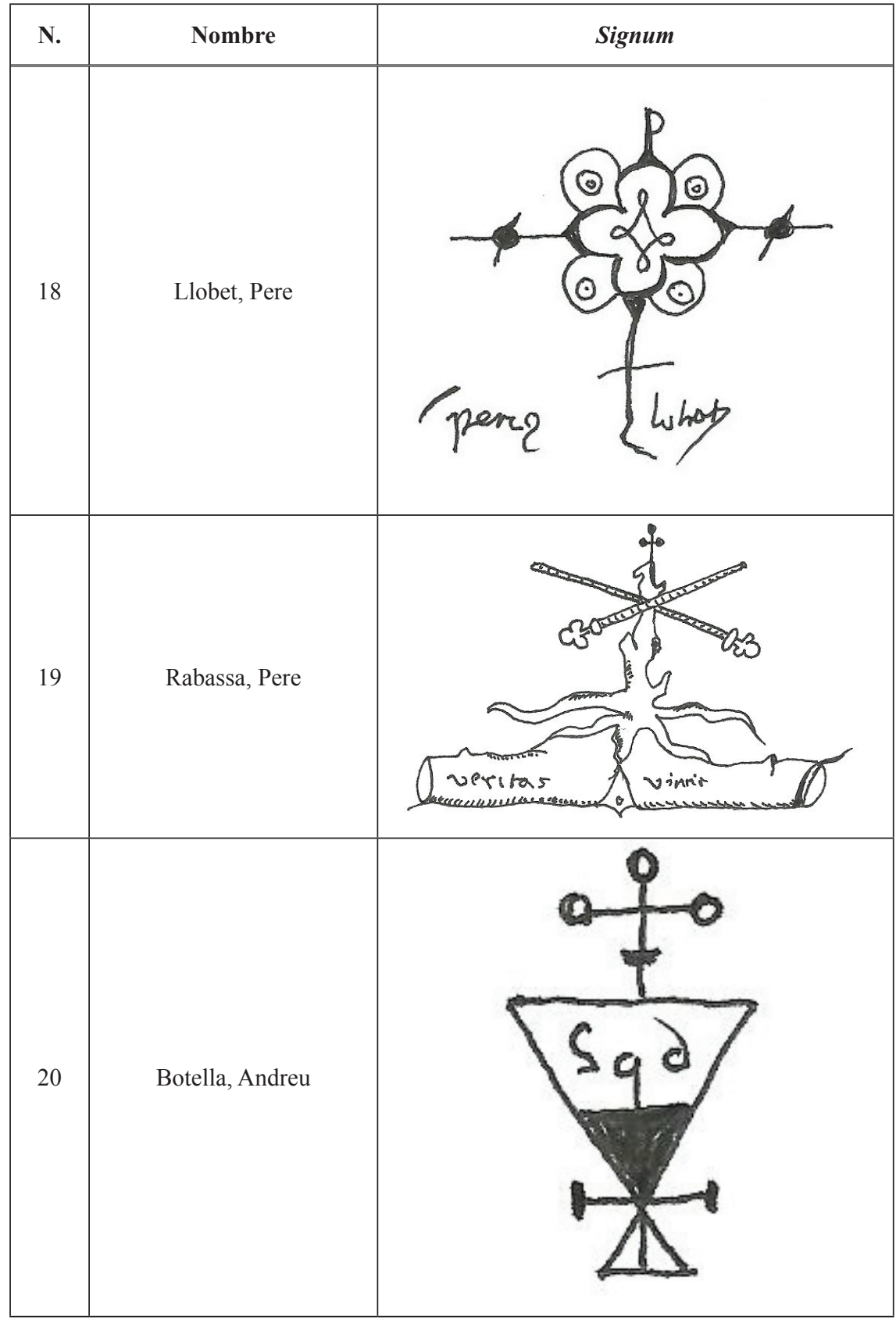




N. Nombre




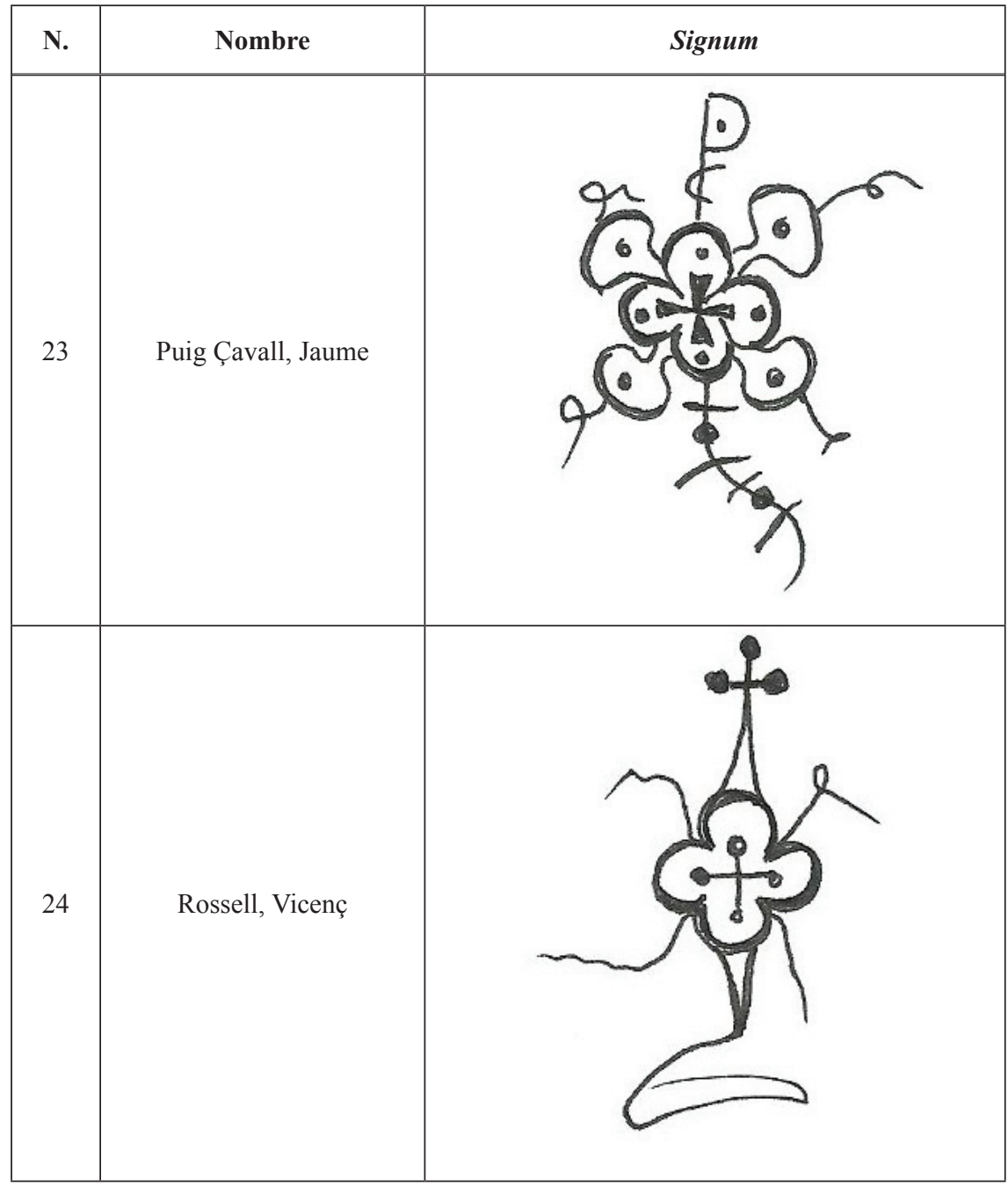




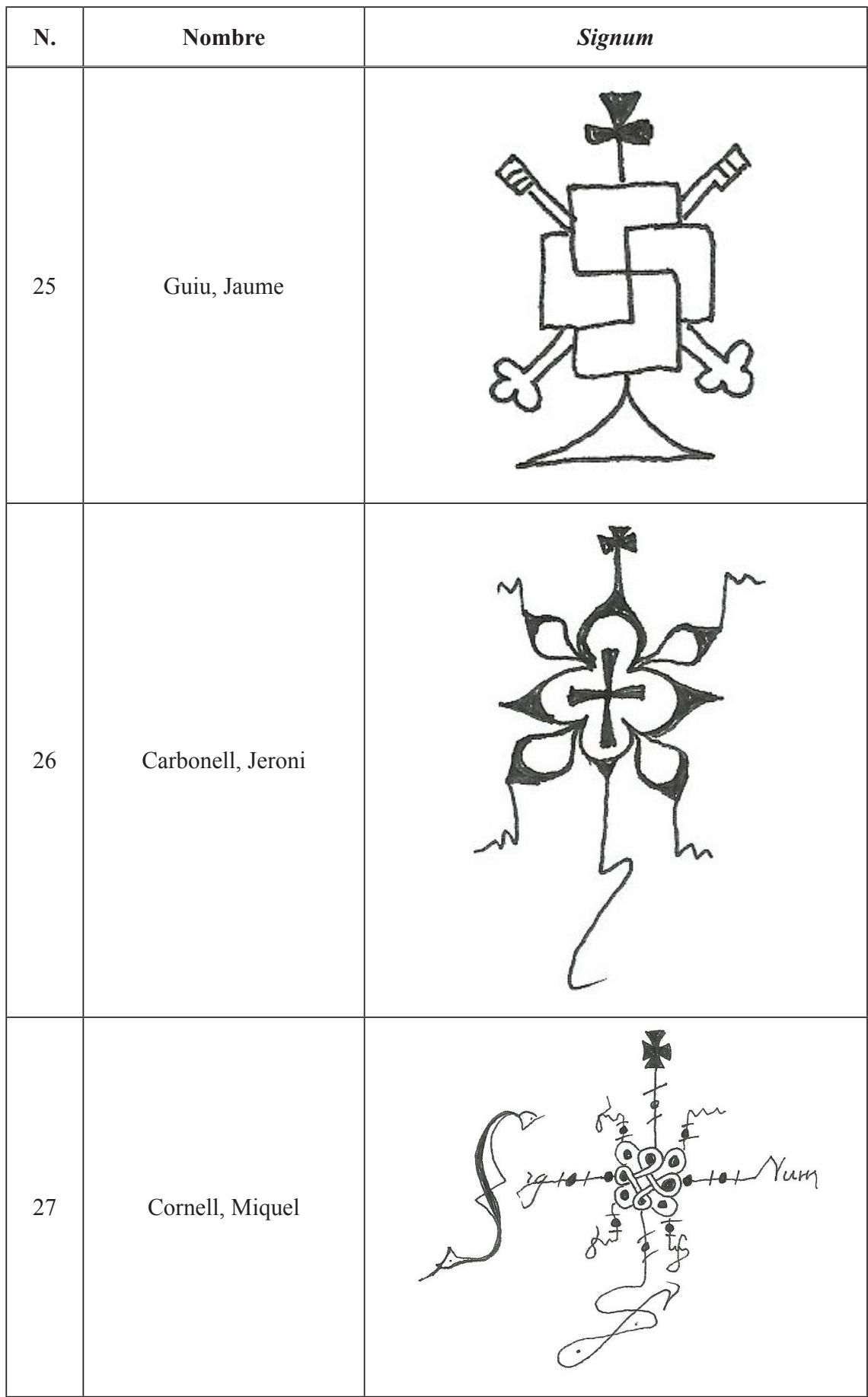




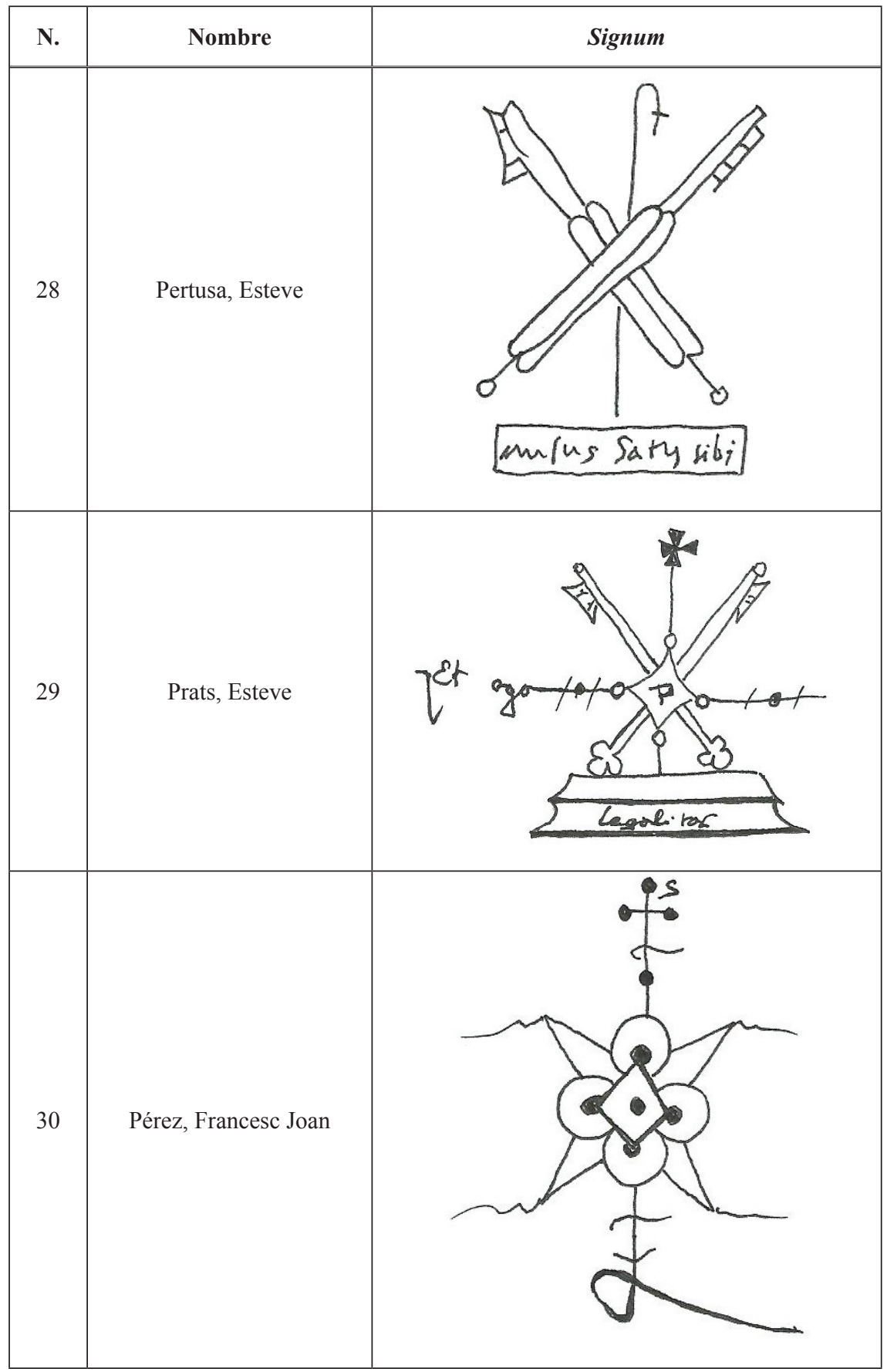




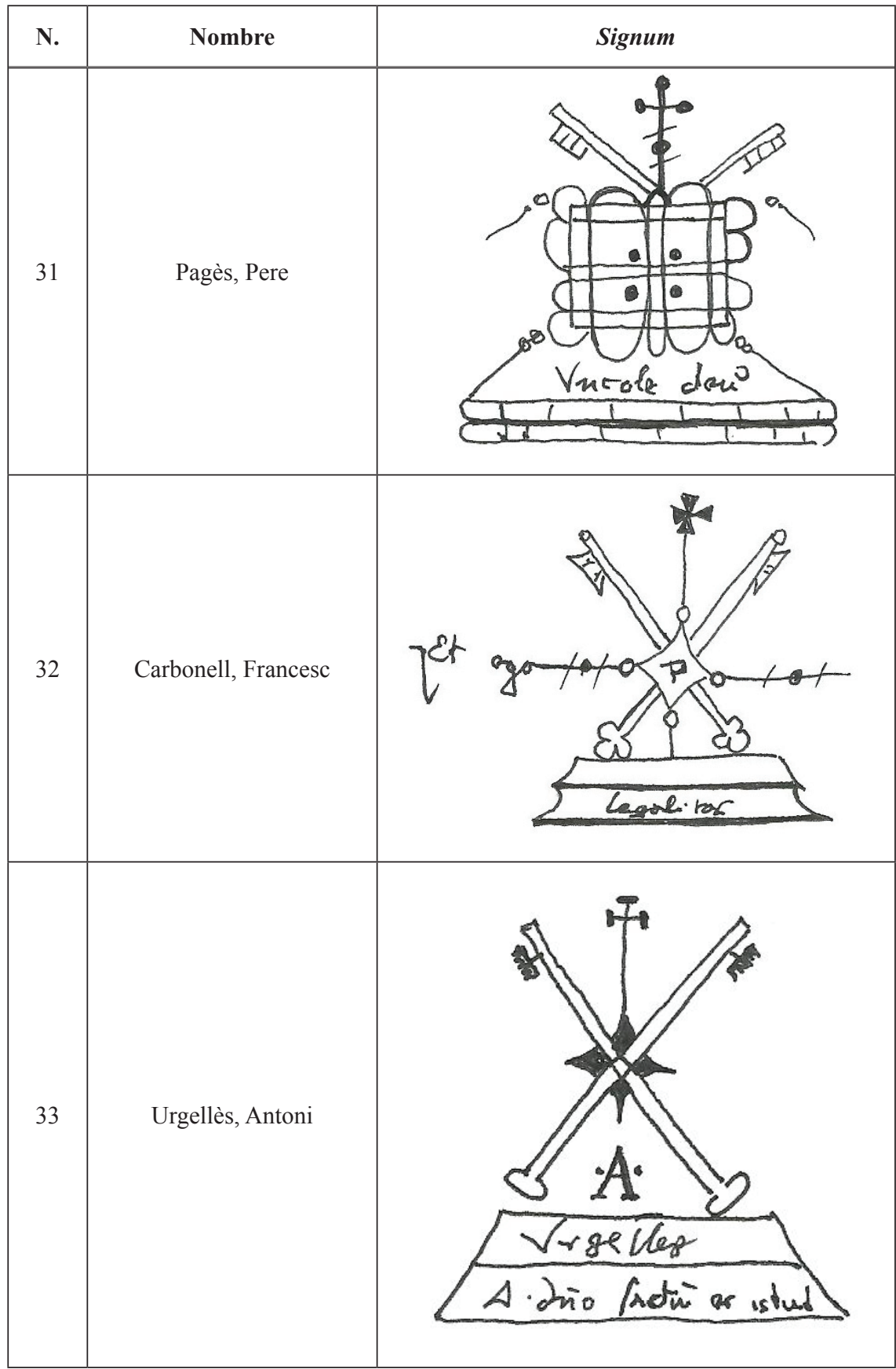




Nombre Jeroni 34 Renull, Albert




Nolis, Jaume




Nombre




Nombre




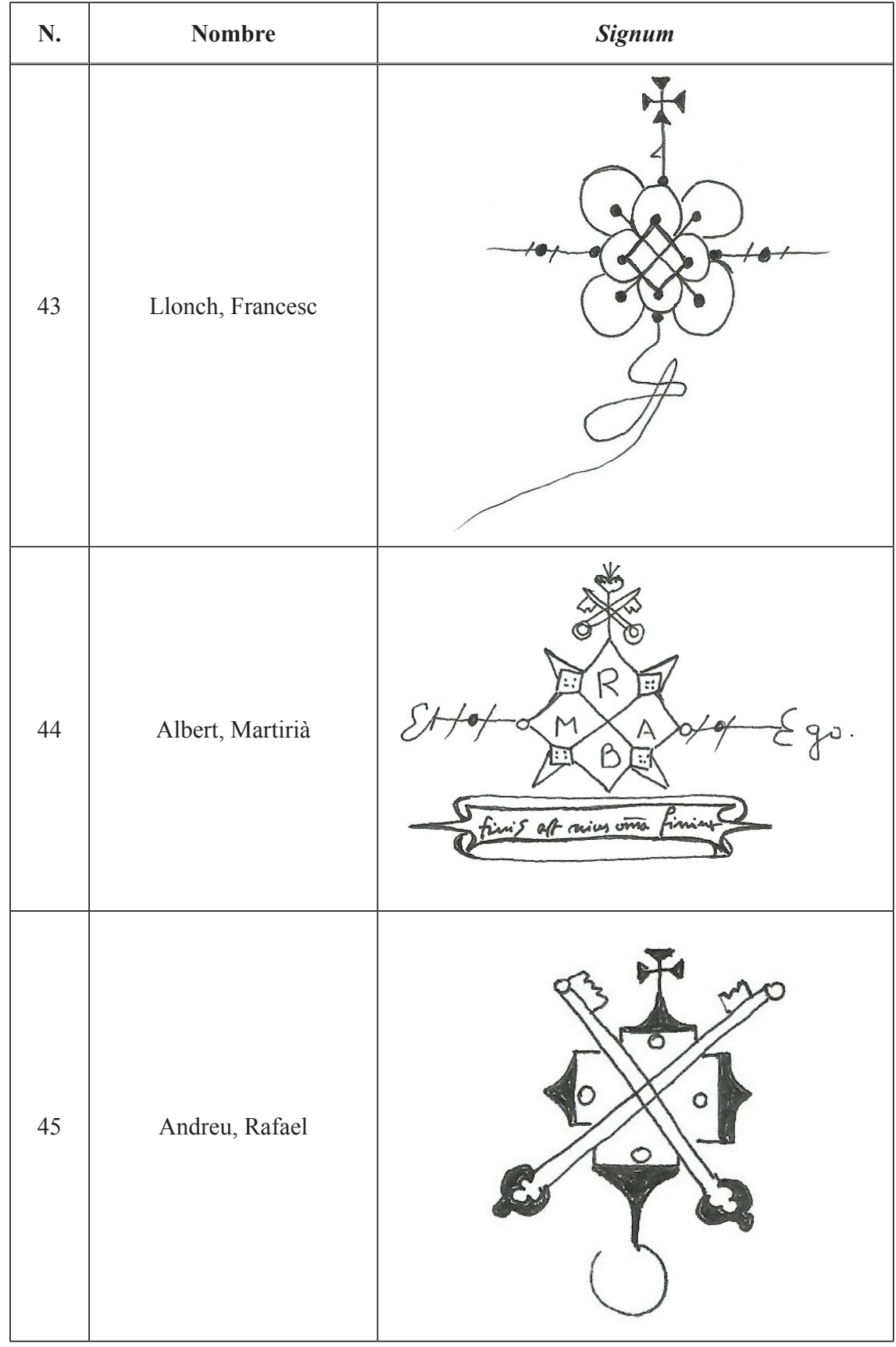




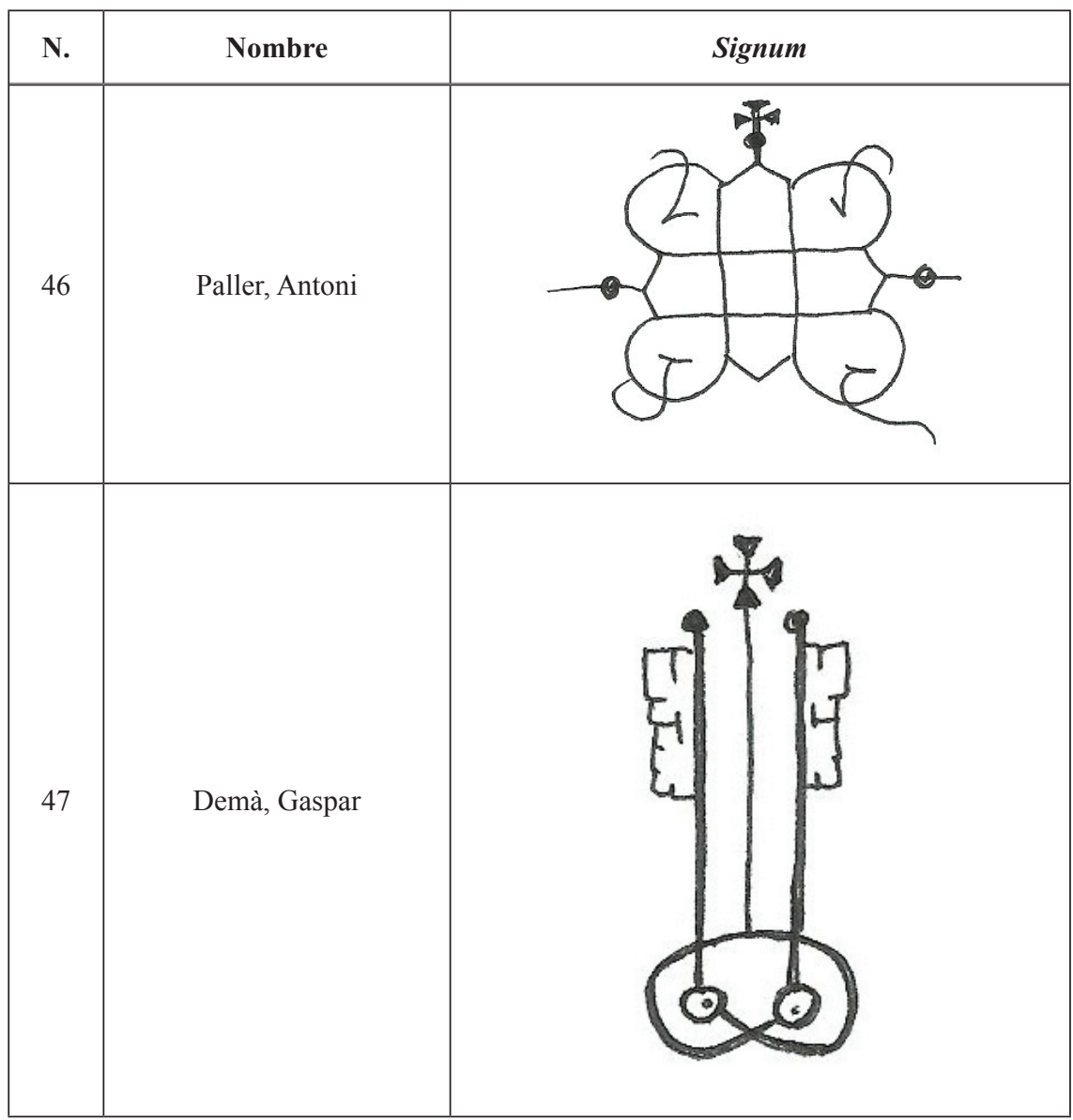




Nombre




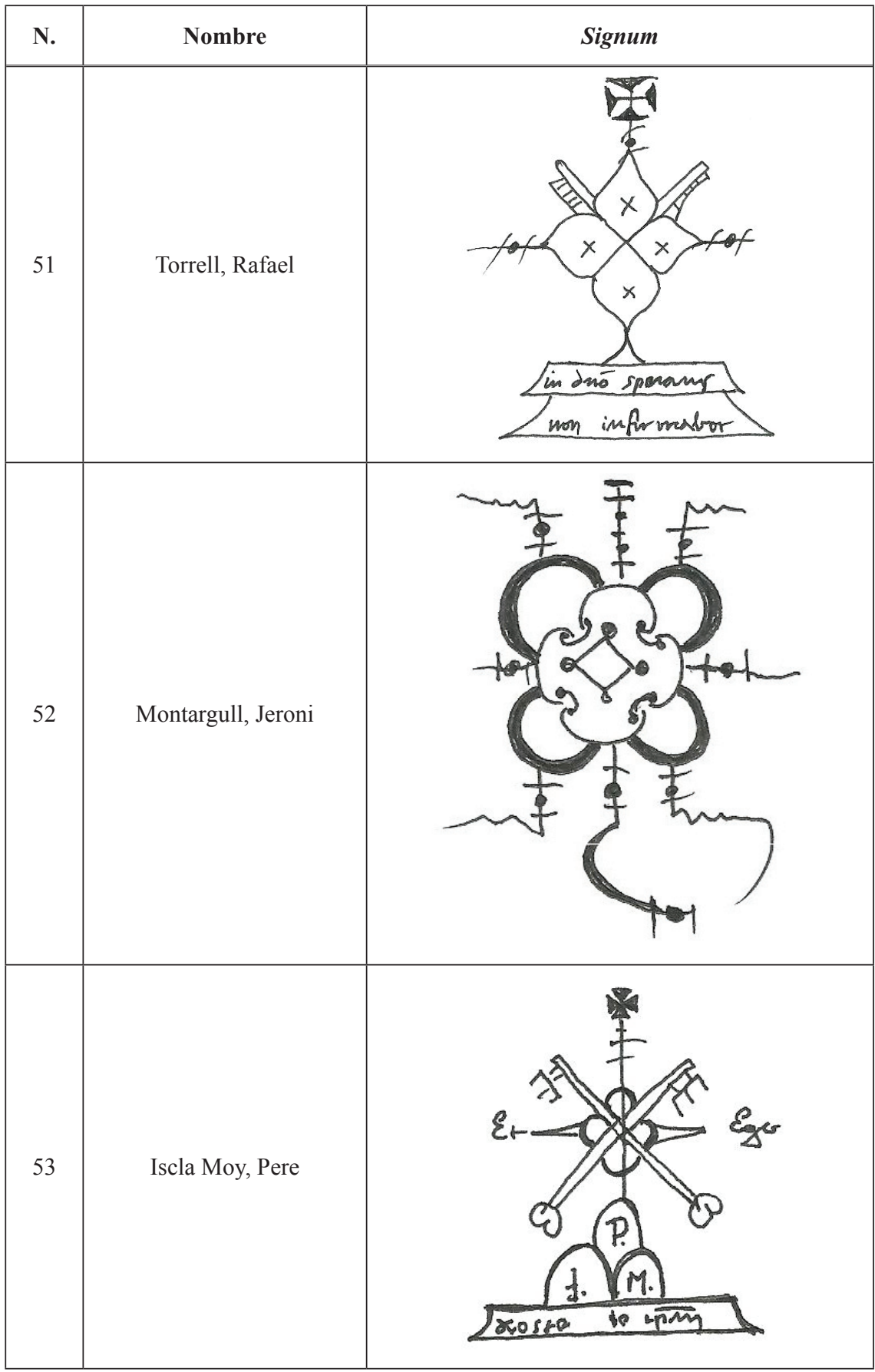




Randoní, Nicolau




Nombre




Calassanc, Jeroni




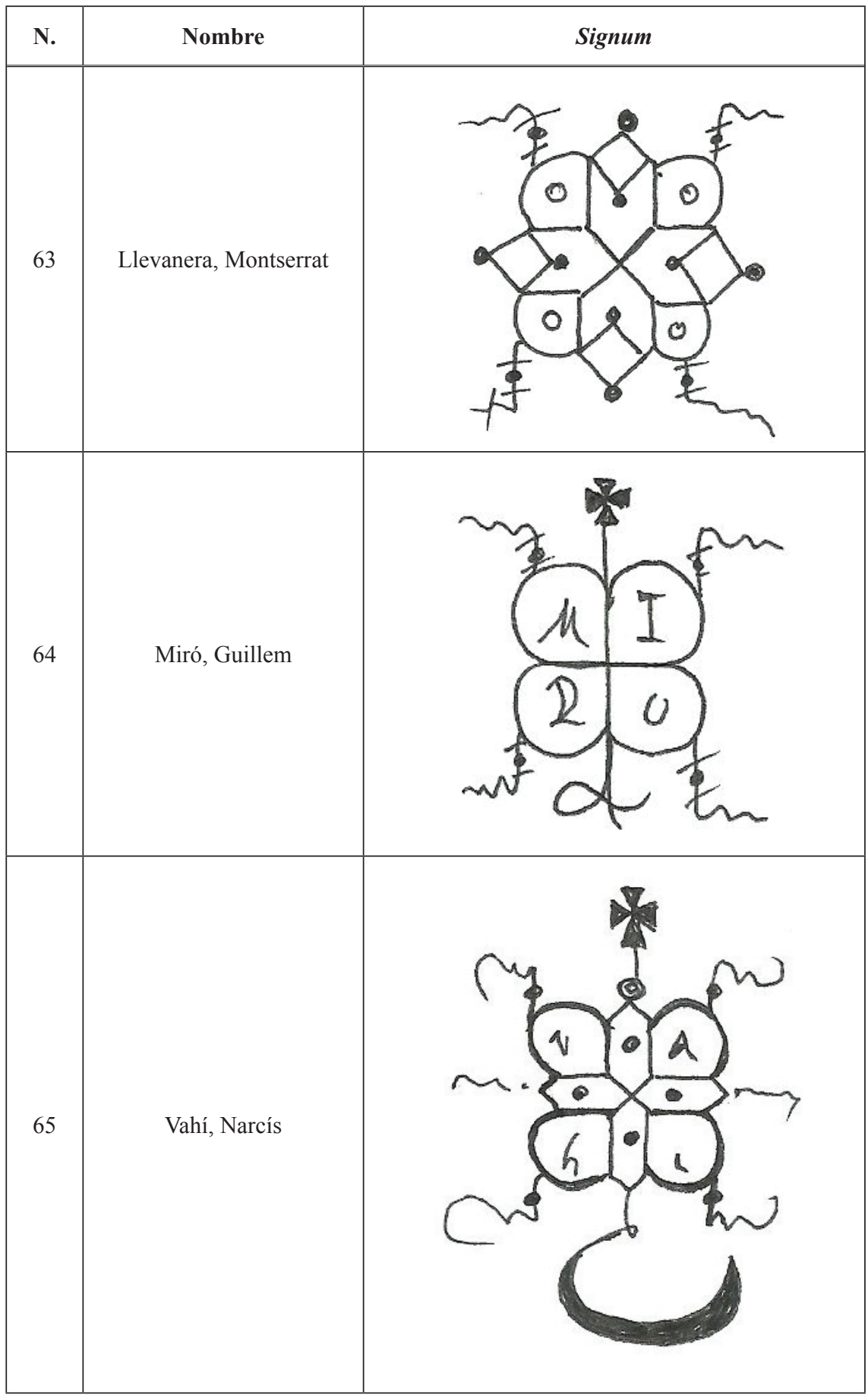




Nombre




Nombre




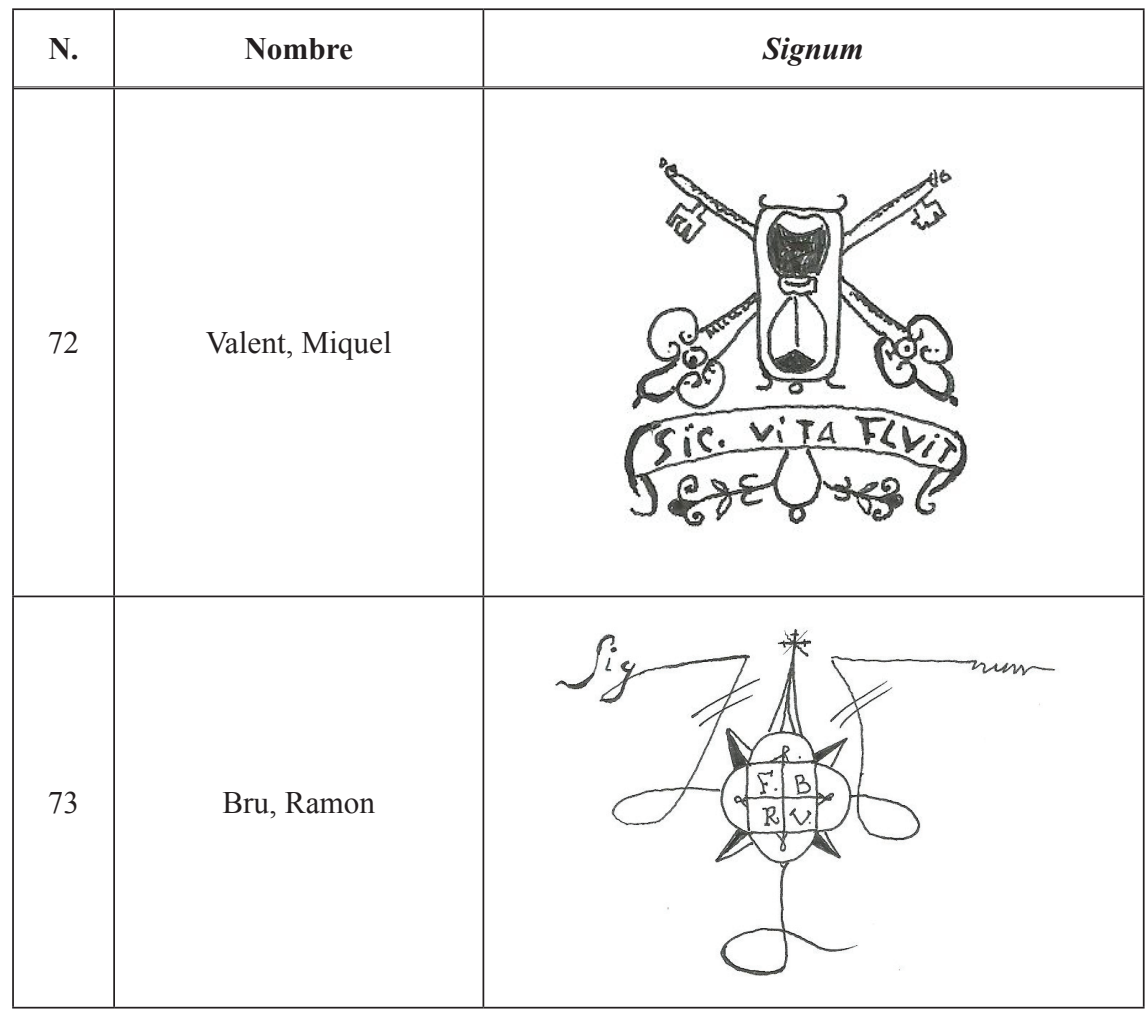

\section{BIBLIOGRAFÍA:}

ADROER, M.A., SERNA, E., SOLER, S. Catàleg dels protocols notarials del districte de Figueres (II), Barcelona: Fundació Noguera, 2004.

CARRIÓ-INVERNIZZI, D. "Los catalanes en Roma y la Iglesia de Santa María de Montserrat (1640-1670)", Pedralbes 28 (2008) pp. 571-584.

COMPANYS I FARRERONS, I. Catàleg dels protocols notarials de Tarragona (1472-1899), Barcelona: Fundació Noguera, 2000.

CORBO, A.M. "Relazione descrittiva degli archivi notarili Romani dei secoli XIV-XV nell'Archivio di Stato e nell'Archivio Capitolino", en BREZZI, P., LEE, E. (coord.) Gli atti privati nel tardo medioevo: fonti per la storia sociale, Roma: Istituto di Studi Romani, 1984, pp. 49-67.

CROCE, B. España en la vida del Renacimiento, Sevilla: Ed. Renacimiento, 2007. DANDELET, Th.J. La Roma española (1500-1700), Barcelona: Ed. Crítica, 2002. DELUMEAU, J. Rome au XVIe siècle, París: Hachette, 1975.

ESPOSITO, A. "Roma e i suoi notai: Le diverse realtà di una città capitale (fine sec. XIV-inizio sec. XVI)", en PIERGIOVANNI, V. (ed.) Il notaio e la città: 
essere notaio: $i$ tempi e i luoghi, sec. XII-XV, Milano: Giuffrè Ed., 2009, pp. 93-111.

FALUCCI, C., MARRONE, A., SANTONI, P. Introduzzion. Archivio Urbano. Sezione II - Notai e scrittori dell'Archivio della Romana Curia (1507-1621), Roma, 2006.

FERNÁNDEZ ALONSO, J. "Las iglesias nacionales de España en Roma. Sus orígenes", Anthologica Annua 4(1956), pp. 9-122.

-. "El hospital de San Nicolás de los Catalanes en Roma. Nuevos documentos de Nicolás Conill”, Anthologica Annua 30-31 (1983-1984), pp. 363-377.

FRANÇOIS, A. Elenco di notari che rogarono atti in Roma dal secolo XIV all'anno 1886, Roma, 1886.

GINEBRA, R. "Les escrivanies eclesiàstiques a Catalunya”, en Actes del II Congrés d'Història del Notariat Català, Barcelona:Fundació Noguera, 2000, pp. 89-160.

LEE, E. (ed.) 'Descriptio Urbis'. The Roman Census of 1527, Roma: Ed. Bulzoni, 1985.

LESELLIER, J. "Notaries et archives de la Curie Romaine (1507-1625): les notaires français à Rome", Mélanges d'Archéologie et d'Histoire 50(1933), pp. 250-275. http://dx.doi.org/10.3406/mefr.1933.7239

LOMBARDO, M.L. Il notaio romano tra sovranita' pontificia e autonomia comunale (Secoli XIV-XVI), Milano: Giuffrè Ed., 2012.

MORI, E. "L'Archivio Generale Urbano", en DE VIZIO, R. (coord.) Repertorio dei notari romani dal 1348 al 1927, dall' 'Elenco'di Achille François, Roma: Fondazione Marco Besso, 2011, pp. XXXIII-XLII.

PIÑOL ALABART, D. El notariat públic al Camp de Tarragona. Història, acrivitat, escriptura i societat (segles XIII-XIV), Barcelona: Fundación Noguera, 2000.

PUEYO, P. "Notarios altoaragoneses en Roma (1507-1625)", en XIV Congresso di Storia della Corona d'Aragona, vol. IV, Sassari: Carlo Delfino Editore, 1990, pp. 251-264.

RAMON I VINYES, S., FUENTES I GASÓ, M.M. Inventari dels protocols notarials de l'AHAT, Barcelona: Departament de Cultura de la Generalitat de Catalunya, 1987.

RAMON, S., RICOMÀ, F.X. (eds.) Índex Vell. Índex dels documents de l'Arxiu de l'Arquebisbe, 1679, Tarragona: Publicacions de la Diputació de Tarragona, 1997 ,

RECASENS, J.M. La ciutat de Tarragona, vol.2, Barcelona: Ed. Barcino, 1975.

RIUS SERRA, J. "Catalanes y aragoneses en la Corte de Calixto III", Analecta Sacra Tarraconensia, III(1927), pp. 120-330.

SAN MARTINI BARROVECCHIO, M.L. "Il collegio degli scrittori dell'Archivio della Curia romana e il suo ufficio notarile (secoli XVI-XIX)", en Studi in onore di Leopoldo Sandri, Roma: Scuola speciale per archivisti e bibliotecari dell’Università di Roma, 1983, pp. 847-872. 
VAQUERO PIÑEIRO, M. "La presencia de los españoles en la economía romana (1500-1527)", En la España medieval 16 (1993), pp. 287-305.

-. "Mercaderes catalanes y valencianos en el consulado de Roma", Revista d'Història Medieval 9 (1998), pp. 155-169.

- La renta y las casas. El patrimonio inmobiliario de Santiago de los españoles de Roma entre los siglos XV y XVII, Roma: L'Erma di Bretschneider, 1999.

VERDI, O. 'L'Archivio del Collegio dei notai capitolini (1348-1628)", en DE VIZIO, R. (coord.) Repertorio dei notari romani dal 1348 al 1927, dall' 'Elenco' di Achille François, Roma: Fondazione Marco Besso, 2011, pp. XXV-XXXII.

VIEILLARD, J. "Notes sur l'hospice Saint-Nicolas des Catalans à Rome au Moyen Age", en Mélanges d'Archéologie et d'Historie, 50 (1933), pp. 183-193.

VINCKE, J. "Inicios del hospital Cathalanorum et Aragonensium en Roma", Hispania Sacra 11(1958), pp.139-156.

VOVELLE, M. La morte e l'Occidente. Dal 1300 ai giorni nostri, Roma-Bari: Ed. Laterza, 2000.

Fecha de recepción del artículo: octubre 2012

Fecha de aceptación y versión final: octubre 2013 